\title{
Analysing the effect of stand density and site conditions on structure and growth of oak species using Nelder trials along an environmental gradient: experimental design, evaluation methods, and results
}

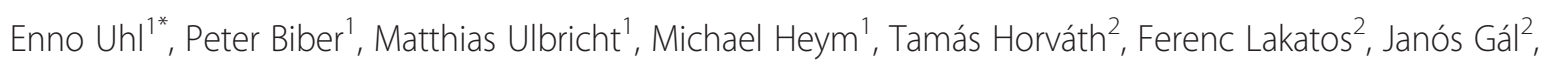
Leonhard Steinacker ${ }^{1}$, Giustino Tonon ${ }^{3}$, Maurizio Ventura ${ }^{3}$ and Hans Pretzsch ${ }^{1}$

\begin{abstract}
Background: Most current approaches in forest science and practice require information about structure and growth of individual trees rather than - or in addition to - sum and mean values of growth and yield at forest stand level as provided by classic experimental designs. By inventing the wheel design, Nelder provided the possibility to turn to the individual tree as basic information unit. Such trials provide valuable insights into the dependency of growth on stand density at particular sites.

Methods: Here, we present an extension of the original design and evaluation by Nelder. (i) We established Nelder wheels along an environmental gradient through Europe in atlantic climate in Belgium and Germany, Mediterranean climate in Italy, continental climate in Hungary as well as on high land climate in Mexico. Such disjunct Nelder wheels along an environmental gradient can be regarded and analysed as a two-factor design with the factors of site condition and stand density. (ii) We present an advanced statistical approach to evaluate density dependent growth dynamics of trees planted in form of the Nelder design, which considers spatio-temporal autocorrelation. (iii) We prove the usefulness of the methods in improving ecological theory concerning density related productivity, trade-offs between facilitation and competition, and allometric relations between size variables.
\end{abstract}

Results: First evaluations based on remeasured Nelder wheels in oak (Quercus robur L.) show a size growth differentiation during the first observation period. In particular, height growth is accelerated under higher competition indicating facilitation effects. We detect furthermore a high variability in allometric relations.

Conclusions: The proposed design, methods, and results are discussed regarding their impact on forest practice, model building, and ecological theory. We conclude that the extended Nelder approach is highly efficient in providing currently lacking individual tree level information.

Keywords: Facilitation; Long-term trial; Nelder; Single tree analyses; Space use efficiency; Stress-gradient-hypothesis; Tree allometry; Quercus

\footnotetext{
* Correspondence: enno.uhl@|rz.tum.de

${ }^{1}$ School of Life Sciences Weihenstephan, Technische Universitaet Muenchen,

Hans-Carl-von-Carlowitz-Platz 2, 85354 Freising, Germany

Full list of author information is available at the end of the article
} 


\section{Background}

The need for single tree information in forest ecosystem analysis

Especially in advanced phases of stand development, high local stand density around a tree may cause competition for resources, growth reduction of the tree, or even its dropout resulting in self-thinning on stand level. However, high densities may also cause positive effects on plant growth. Competitive and facilitative effects may occur simultaneously. Neighbouring plants may compete for contested resources, such as light or water, when these are not sufficient for all. At the same time they may facilitate each other, e.g. by reducing wind speed and thus lowering transpiration or by hydraulic redistribution, which may improve the neighbour's water supply.

The net effect of co-occurring competition and facilitation on growth is of practical interest. Positive density effects on weed suppression and stabilization may exceed negative effects of resource competition, so that finally trees growing in community may outperform their solitarily growing neighbours.

According to the stress-gradient hypothesis, such trade-offs between competition and facilitation and the resulting net effects vary along ecological gradients. The stress-gradient hypothesis ( $\mathrm{SGH}$ ) states facilitation to dominate species interactions under high stress levels (as e.g. strong resource limitation) whereas competition is claimed to prevail in the absence of limitation (Callaway and Walker 1997; Holmgren et al. 1997). Benefits of species mixing are predicted in harsh and neutral, but negative effects in favorable environments (Callaway and Walker 1997). The net effect of facilitation and competition may also vary temporarily, so that species mixing yields higher benefits in low-growth or stress years compared to high-growth years (del Rio et al. 2014).

Because of their broad range and gradual increase of local densities from the periphery to the centre, Nelder trials (Nelder 1962, Fig. 1) can contribute to separate between the positive and negative effects of density. They allow identifying the break-even level of density, where its positive effects turn into negative net effects.

Especially in the early stand development phase, positive effects of density such as control of competing weed, avoidance of overheating by mutual shading or dilution effect against herbivores may have the upper hand and may decrease from the inner to the outer parts of a Nelder wheel. In contrast, resource supply of the individual plant may increase from the inner to the outer circle because of the larger growing area per tree. Our analysis will address the interaction between these counteracting effects and

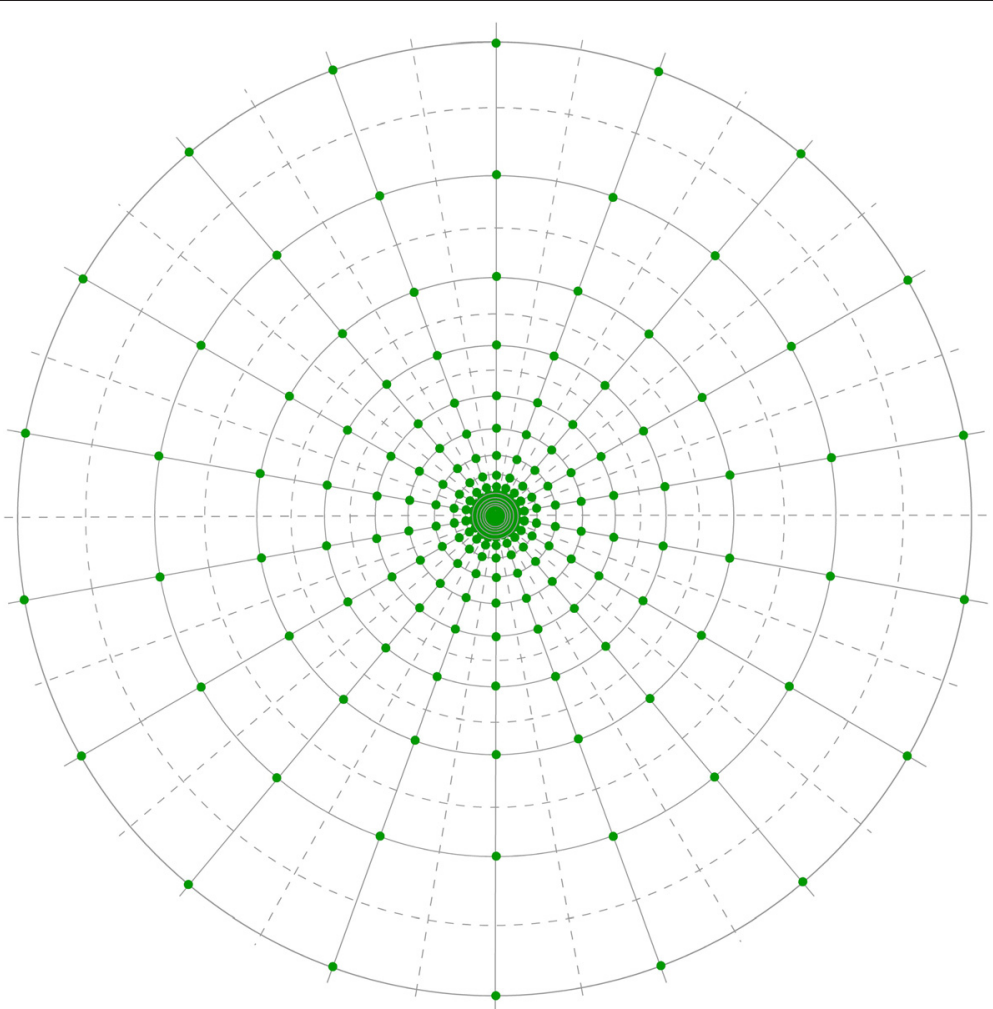

Fig. 1 Spacing trial design according to Nelder (1962). Plant positions (green dots) are defined by intersection points of concentric circles and radial spokes 
quantify the net effect. Any positive effects in the juvenile stage are highly relevant for the whole timespan of stand development due to the long lasting compound interest effect of early lead.

The above-mentioned effects are especially important for an enhanced understanding of the complex-structured and mixed species forests. These are increasingly favoured in practice, as they are widely held to outperform pure stands in providing a broad range of ecosystem functions and services. While homogeneous pure stands can adequately be described by mean and sum values per hectare at stand level, more complex stands require more complex approaches reaching down to the individual tree or even organ level. The transition to more structured and mixed forests increases the need for information on individual tree growth in dependence on the local environmental conditions, as complex stands and their dynamics are perceived as a mosaic of individual trees and their interactions.

This paradigm change from a stand level focus to a single-tree view creates a new interest in Nelder designs, because they allow a very effective analysis of tree dynamics along an almost continuous spacing gradient. However, the tree-level-view implies new conceptual and statistical challenges for a meaningful experiment evaluation.

\section{Transition from stand-based to individual tree-based evaluation of Nelder wheels}

When applied to forests, so far, Nelder trials were mainly used for exploring growing stock and productivity in terms of dendrometrical mean and sum values per hectare. Each tree is permanently assigned to a fix growing area defined by the distance to the adjacent circles' trees and to the trees on the same circle but on the adjacent spokes. Relating the growing stock or growth itself to this growing area can provide practically relevant information about the dependency between stand density and productivity and enable, e.g. the derivation of the optimum stand density for growth and yield (Dippel 1982; Spellmann and Nagel 1992).

If a tree drops out from a Nelder wheel in the course of stand development, this inevitably changes the growing area of at least its eight nearest neighbours and reduces the sample size of trees with continuously constant initial spacing and respective growing area (Fig. 1; Kuehne et al. 2013). This is a minor problem when dealing with annual or biennial agricultural crops for which Nelder originally developed the wheel design. However, during the 50-100 years lasting observation time of wheels stocked with trees, dropouts occur continuously and inevitably. Over time, this hardly leaves any trees in their original spatial constellation, and thus calls the standard evaluation of their stock and growth per initial growing area, or even the continuation of the whole experiment, into question.
Because of the changing growing area and decreasing sample size due to aging and self-thinning, more and more difficulties arose in deriving reliable mean tree and sum values per hectare from Nelder trials. Parallely, triggered by paradigm changes in forest modelling (Munro 1974) and forest policy, science and practice turned from a stand-focussed view towards an individual tree based analysis and management (Grimm 1999; Pretzsch 2009, pp 291-336;). While the changing growing area problem hampers classic stand level Nelder design evaluations, especially when mid- or long-term observations are dealt with, single tree focussed evaluations become utterly useless if this point is not taken into account. It calls for including fine-tuned measures for individual tree's growing space and competition. From a statistical point of view, spatial and temporal autocorrelation has to be considered in an individual-tree based Nelder-wheel evaluation. Neither are subsequent measurements of a tree statistically independent nor are the measurements of neighbouring trees. Ignoring both autocorrelation aspects would violate basic assumptions of classic statistical methods and lead to biased results and overestimated significances.

Nelder trials were rarely evaluated at individual tree level using competition indices so far, as done by Vanclay et al. (2013) and Tennent (1975). However, to our knowledge autocorrelation effects, especially spatial ones which emerge from the single tree approach, have not yet been considered in the context of Nelder trial evaluations. With this study, we introduce a method for evaluating Nelder trials on single tree level that combines a spatially explicit view on competition with a spatial autocorrelation concept. Moreover, we apply the approach for analyzing the development of individual oaks in dependence on stand density and site conditions.

\section{Research questions}

As described above, this paper introduces an evaluation approach for Nelder trials that avoids problems typically arising when the single tree level is of interest. We test the approach by using several newly established Nelder wheels with oak species and by focusing on the following questions:

1) How does growth of trees perform by varying growing space and site conditions?

2) Does tree allometry change with varying growing space and site conditions?

3) Does growing space efficiency vary depending on growing space and site conditions?

\section{Methods}

Set of Nelder trials along an ecological gradient

This study makes use of tree and tree growth information taken from seven Nelder-trials established during 
2008 and 2014. Six out of our trial sites are located in different European countries; one was set up in Mexico (Fig. 2, Table 1). Although this study restricts to the three sites ING650 (Ingolstadt, Germany), GYO651 (Györ, Hungary), and SAN653 (Sant'Agata, Italy) because only these were measured twice so far, we give a short overview of all trial sites here. Each trial comprises two Nelderwheels in immediate vicinity to each other. Each wheel covers a growing space gradient from $0.05 \mathrm{~m}^{2}$ up to $400 \mathrm{~m}^{2}$ per plant, being equivalent to stand densities of 25 up to 200,000 plants per hectare. This emulates a range of stand densities as found in natural regeneration down to solitary growing trees.

Following the concept of Nelder (1962), these settings bear a geometrically incrementation factor of $a=1.413$ and lead to a wheel design with 18 spokes, having a constant angle distance of $20^{\circ}$, and 14 circles including $14 \times 18=252$ plants per wheel. The outermost circle serves as buffer for edge effects, and is thus not included into any analysis. Except for the trials GYO651 and PUE656 (Puebla, Mexico) we planted the Nelder-wheels with Pedunculate oak (Quercus robur L.). At GYO651 and PUE656 Sessile oak (Quercus petraea (Mattuschka) Liebl.) and Neatleaf oak (Quercus rugosa Nee.) were chosen as the typical oak species at those sites (Table 1). In every case, local provenances were used. Plant ages at the trials' establishment were one up to three years with heights between 30 and $70 \mathrm{~cm}$. ING650 and BRU655 were established on clear-cuts within forests and NEC652 and GYO651 on former agriculturally used areas within forests. SAN653 and GYO652 were set up outside forests on erstwhile farmland. An area nearly without standing stock within a natural forest was planted in case of PUE656. The trials in Europe cover soils from loess or alluvial sediments with good nutrient supply, the same is true for the deep clay soil of the Mexican site. Climate ranges between atlantic (Brussels), subcontinental (Györ), sub Mediterranean (Sant'Agata), and subtropical highland conditions (Puebla). Mean temperatures at the European sites vary between $8.2{ }^{\circ} \mathrm{C}$ (Ingolstadt) and $13.2{ }^{\circ} \mathrm{C}$ (Sant'Agata), while the long-term average at Puebla amounts to $17.1{ }^{\circ} \mathrm{C}$. Mean annual precipitation is lowest at the Györ site $(537 \mathrm{~mm})$, highest at Brussels $(820 \mathrm{~mm})$ and Puebla $(900 \mathrm{~mm})$, respectively.

\section{Measurements and derivation of tree dimensions and increment values}

The coordinates of each plant were recorded. Measurements of single trees comprise the diameter at root collar $(d)$, if existent the diameter at breast height $(d b h)$, diameter at crown base $(d c b)$, tree height $(h)$ and height of crown base $(h c b)$. Additional crown properties like radius $(c r)$ in eight cardinal directions and deflection from stem base were surveyed. By now, no mortality due to competition could be observed. In some cases weed mowing caused cutting of trees. These were immediately replaced by new trees with similar tree dimensions from a surrounding buffer zone. The buffer zones were established with the same plant material (provenance, assortment) as the wheels themselves.

In analyses, we always refer to diameter at root collar (d). Basal area $(b a)$ was calculated from $d$, plant volume
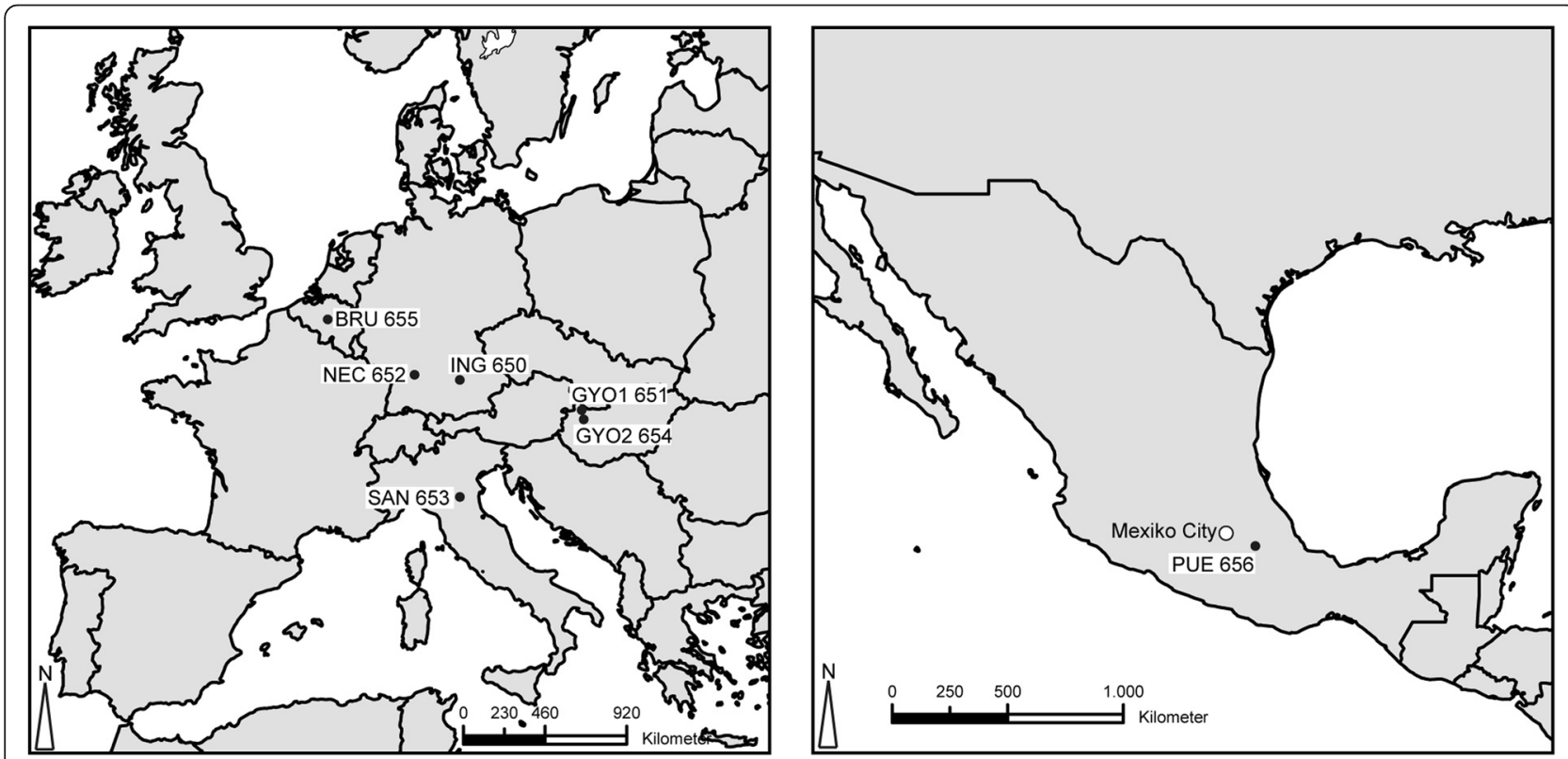

Fig. 2 Locations of our Nelder-trials with oak species in Europe (left) and Mexico (right) 
Table 1 Location and growing conditions, plant species, plot establishment and survey dates of the Nelder trials reported in this study

\begin{tabular}{|c|c|c|c|c|c|c|c|c|c|c|c|c|}
\hline Trial & Location & Longitude $\left(^{\circ}\right)$ & Latitude $\left(^{\circ}\right)$ & Altitude (m) & Soil characteristics & Mat $\left({ }^{\circ} \mathrm{C}\right)$ & Map (mm) & Tree species & $\begin{array}{l}\text { Year of } \\
\text { planting }\end{array}$ & $\begin{array}{l}\text { Tree age at } \\
\text { planting (yr) }\end{array}$ & $\begin{array}{l}\text { First survey } \\
\text { (age) }\end{array}$ & $\begin{array}{l}\text { Second survey } \\
\text { (age) }\end{array}$ \\
\hline ING650 & Ingolstadt (Germany) & $11.49 \mathrm{E}$ & $48.86 \mathrm{~N}$ & 460 & $\begin{array}{l}\text { Loess cover above tertiary } \\
\text { limestone weathering } \\
\text { products }\end{array}$ & 8.2 & 670 & Quercus robur L. & 2008 (a) & 2 & $2010(4)$ & $2012(6)$ \\
\hline GYO651 & Györ (Hungary) & $17.60 \mathrm{E}$ & $47.79 \mathrm{~N}$ & 110 & Alluvial loam & 11.1 & 537 & Quercus robur L. & 2009 (a) & 3 & $2010(4)$ & $2013(7)$ \\
\hline NEC652 & Neckarsulm (Germany) & $9.35 E$ & $49.05 \mathrm{~N}$ & 380 & $\begin{array}{l}\text { Superficial loam cover with } \\
\text { temporary water-logged } \\
\text { conditions }\end{array}$ & 9.1 & 760 & Quercus robur L. & 2010 (a) & 1 & $2013(4)$ & - \\
\hline SAN653 & Sant'Agata (Italy) & $11.10 \mathrm{E}$ & $44.46 \mathrm{~N}$ & 25 & Deep alluvial loam & 13.2 & 660 & Quercus robur L. & 2010 (a) & 2 & 2011 (3) & $2012(4)$ \\
\hline GYO654 & Györ (Hungary) & $17.47 \mathrm{E}$ & $47.30 \mathrm{~N}$ & 181 & Very deep loess & 9.8 & 570 & $\begin{array}{l}\text { Quercus petraea } \\
\text { (Mattuschka.) Liebl. }\end{array}$ & 2014 (s) & 1 & - & - \\
\hline BRU655 & Brussels (Belgium) & $4.26 \mathrm{E}$ & $50.44 \mathrm{~N}$ & 130 & Deep loess & 9.7 & 820 & Quercus robur L. & 2012 (a) & 2 & - & - \\
\hline PUE656 & Puebla (Mexico) & $98.05 \mathrm{~W}$ & $19.01 \mathrm{~N}$ & 2350 & Deep clay & 17.1 & 900 & Quercus rugosa Nee. & 2014 (a) & 1 & - & - \\
\hline
\end{tabular}

Mat mean annual temperature, Map mean annual precipitation, $N$ north, $E$ east, $W$ west, $a$ autumn, $s$ spring 
$v$ was derived by using the cone formula $v=\frac{1}{3} \cdot b a \cdot h$. We also calculated crown length $(c l)$ and crown cross section area $(c s a)$ by applying the square root of the quadratic mean of the eight radii $c r\left(c s a=\sqrt{\left(c r+c r_{\mathrm{NW}}^{2}+\ldots+c r_{\mathrm{NE}}^{2}\right) / 8}\right)$. Crown volume $c v$ was calculated by multiplying $c s a$ and $c l$. Annual rates of increment $\left(i_{d}, i_{h}, i_{v}, i_{c l}, i_{c s a}, i_{c v}\right)$ were estimated by dividing the final tree size by the time span from planting to last measurement.

\section{Detecting tree allometry from successive dendrometrical measurement}

As the base information for research question 2, we quantify the morphological changes of the plants through the periodic allometric slope (synonym: allometric exponent)

$$
\alpha_{i}=\frac{\ln \left(y_{i+1}\right)-\ln \left(y_{i}\right)}{\ln \left(x_{i+1}\right)-\ln \left(x_{i}\right)}=\frac{\ln \left(y_{i+1} / y_{i}\right)}{\ln \left(x_{i+1} / x_{i}\right)}
$$

Here, $y$ and $x$ are different attributes of the same plant, e.g. height and volume. If $i$ and $i+1$ denote subsequent times of measurement, then $\alpha_{i}$ is valid for the period between the surveys $i$ and $i+1$. The calculation above is most convenient when $y_{i}, y_{i+1}, x_{i}$, and $x_{i+1}$ are available from subsequent measurements as is the case in this study (Pretzsch and Schütze 2005). Suppose, we have measured heights $h_{1}$ and $h_{2}$ and volumes $v_{1}$ and $v_{2}$ at the same tree in two successive surveys, and the calculation of $\alpha_{h, v}=\ln \left(h_{2} / h_{1}\right) / \ln \left(v_{2} / v_{1}\right)$ yields $\alpha_{h, v}=1 / 4$. This would indicate that a volume increase by $1 \%$, the relative height increase amounts to $0.25 \%$. In contrast, $\alpha_{h, v}=1 / 2$ would constitute a relative increase of $0.50 \%$ per $1 \%$ volume growth, i.e. a greater allocation into height compared with volume (Pretzsch 2010).

From our Nelder plots we use the measurements of height $(h)$, tree diameter $(d)$, tree volume $(v)$, crown length $(c l)$, crown cross section area (csa), and crown volume $(c v)$, for calculating each tree's periodic allometric slopes $\alpha_{h, v}, \alpha_{d, v}, \alpha_{c l, v}, \alpha_{c s a, v}$ and $\alpha_{c v, v}$. We use tree volume in all of the slopes, as for these cases the metabolic scaling theory (MST) postulates universally valid values, which can be used as a reference $\left(\alpha_{h, v}=1 / 4\right.$, $\alpha_{d, v}=3 / 8, \alpha_{c l, v}=1 / 4, \alpha_{c s a, v}=1 / 2$, and $\alpha_{c v, v}=3 / 4$; Enquist et al. 1998, 2009). In addition, we calculated the allometric slope for tree height based on diameter $\left(\alpha_{h, d}=2 / 3\right)$.

\section{Evaluation of growing space efficiency}

While the allometric analysis focussed on the withinplant and plant-plant interaction in terms of tree morphology, the following analysis relates the growth to the occupied area. The former approach represents the view of plant biology and physiology on inner- and interindividual variation of plant size and growth. The following approach represents the production ecology perspective (growth per unit area), as it takes into consideration how much growing area is needed to achieve a given growth unit, i.e. it translates the plant growth to the unit area and reflects the growth per area (Zeide 1987; Sterba and Amateis 1998). If we assume growing area as substitute of resource supply, it subsequently indicates the resource use efficiency (Pretzsch 2006, 2014).

In order to quantify the individual plant growth rates we used the mean increment of plant dimensions $\left(i_{d}, i_{h}\right.$, $\left.i_{v}, i_{c l}, i_{c s a}, i_{c v}\right)$. By using the mean annual increment over several years we minimize the effects of biotic and abiotic stressors and stabilize the response variable growth.

Those individual tree increments were related to the growing area of the tree (Pretzsch 2009). The growing area was calculated using Voronoi polygons calculated by using the software R ( $R$ Core Team 2014) with the package deldir (Turner 2014). By this method, the available stand area is completely divided between the standing trees (Pretzsch 2009, pp 313-314). Tree growth characteristics and occupied area provided the elements for calculating the following efficiency parameters $\left(\right.$ eff $=$ growth/area); eff $i_{i_{h}}$ : height growth, eff $f_{i_{d}}$ : diameter growth, eff $f_{i_{v}}$ : volume growth, eff $f_{i_{c}}$ : growth of crown length, eff $i_{\text {csa }}$ : growth in crown cross section area and $e f f_{i_{c v}}$ growth in crown volume.

Information about growing space efficiency is relevant for designing resource use efficient production systems (Zeide 2001). It also reflects the trees' competitive ability to contested resources and by this an essential aspect of individual fitness.

\section{Re-thinking evaluation methods for Nelder trials Competition index as substitute for resource supply}

In the course of tree development on the Nelder wheels, competition-caused mortality is inevitable. As mentioned above, this alters the competitive situation of at least eight surrounding trees. Using simply the growing space defined by a tree's position on a certain spoke and circle therefore does obviously not reflect its competitive status correctly under such conditions. We therefore include competition indices, which quantify the local density around a tree (Biging and Dobbertin 1992, 1995) into the evaluation of Nelder designs. Using the term competition index, we follow the usual terminology, although a given local density and spatial constellation around a tree may cause not only competition but also facilitation, simultaneously. Especially in the early phase of stand development higher density and higher competition indices may be coupled with facilitation overcompensating competition.

We use a local stand density index $\left(S D I_{l}\right)$ as defined below as a distance independent competition index and the Hegyi-index (Hegyi 1974) representing a distancedependent type of competition index. Recently, the same 
index was chosen by Vanclay et al. (2013) for evaluating a mixed species Nelder trial.

For calculating each tree's competition status we applied a search radii having its center on the tree position and whose extension was defined by the mean height of the 100-tallest trees on the whole wheel multiplied by the factor 1.25. Each tree inside the search radius was considered a competitor to the tree of interest.

The $S D I_{1}$ normalizes the stem number per hectare to a mean tree size of $25 \mathrm{~cm}$ according to the formula

$$
S D I_{l}=N\left(\frac{25}{d g}\right)^{-1.605}
$$

Herein, $N$ relates to stem numbers per hectare derived from the stem number and circle area corresponding to the search radius. The variable $d g$ reflects the mean diameter of all trees within the search radius. The exponent -1.605 was chosen according to the stand density rule (Reineke 1933) portraying a general decline of tree number with increasing diameter.

The Hegyi-index takes into account the distance between the tree of interest and its competing neighbours, i.e. the other trees within the search radius, as well as their size relative to the tree of interest. It is computed as

$$
D C I_{j}=\sum_{i=1}^{n}\left(\frac{d_{i}}{d_{j}} \cdot \frac{1}{1+D I S T_{i j}}\right)
$$

The index $i$ reflects any the central tree $j$ 's $n$ neighbor trees within the search radius. DIST $i j$ represents the distance between the central tree and tree $i . d_{i}$ and $d_{j}$ are the diameters of the neighbor tree $i$ and the central tree $j$.

A simple example reveals the relevance of mortality to be considered when estimating the growing situation of trees within Nelder wheels. Figure 3 illustrates the usage of different competition indices for an exemplary tree (No. 55) on ING650, wheel 1. The grey area in Fig. 3a represents the approximated rectangular growing area as resulting from the chosen Nelder design. The black circle in Fig. 3b (local stand density index) and Fig. 3c (Hegyi-index) indicates the search radius for identifying competing neighbour trees. Finally, in Fig. $3 \mathrm{~d}$ the grey area points the growing space after mortality of tree numbers 37 and 38 calculated by Voronoi polygons. In case of using the approximated growing area competition would not change for tree No. 55 if two trees not growing on the same circle as the centre tree have died. But the distance-independent and the distance-dependent competition indices are lowered by $11 \%$ and $14 \%$, respectively, growing space calculated by Voronoi polygons would accelerate by $21 \%$.

\section{Statistical analyses}

For the subsequent statistical analyses, we suggest general additive regression models (GAM, Zuur et al. 2009). They provide a convenient way to combine explanatory variables with linear and non-linear influence on a goal variable inside the same model. The non-linear relationships are modelled as nonparametric smoothing functions in this context. As we cannot a priori assume the relations of interest in this study to be linear, this is an important feature.

In addition to non-linearity, Nelder-designs induce specific statistical traits on tree level that have to be taken into account. First, they inherently carry the problem of spatial correlation among subjects. With other words, dependent on their distance, the measurements at different plants may not be statistically independent, violating a standard assumption of classic regression analyses. Furthermore, repeated measurements at the same plant must be assumed to be not independent either, which applies when a Nelder trial is remeasured after a certain time interval. For dealing with spatial autocorrelation, there exists a broad variety of readily available spatial variance models (Zuur et al. 2009), however, GAMs provide us with a more convenient option for the purpose of this study. As Fahrmeir et al. (2009) state, autocorrelation in statistical models mostly results from unobserved or unobservable explanatory variables. In our context, this might be e.g. microsite or microclimate influences varying with the plant positions. Such growth conditions can be expected to be similar at short and more different at longer distances, causing spatial autocorrelation when not included in the statistical analysis. In order to cover such effects we introduced a twodimensional nonparametric smoothing function $g(E$, $N)$ in each of our GAMs, where $E$ and $N$ express the coordinates of a tree in easting and northing, respectively. In the fitted model, $g$ expresses at any tree position the summary effect of the unobserved or unobservable local influence variables.

For temporal autocorrelation, classical autoregressive models like ARMA or ARIMA exist. We, however, suggest incorporating this as a random effect on plant level instead, due to the robustness such an approach shows in practice. In such a case, a GAM would become a generalized additive mixed model (GAMM, Zuur et al. 2009).

\section{Applied regression models}

The following basic GAM was used for analysing the influence of local stand density/competition on a tree size $y$ (could be $h$ : tree height, $d$ : diameter at root collar, $v$ : tree volume, $c l$ : crown length, $c s a$ : crown cross section area, $c v$ : crown volume), (research question 1). 
(a)

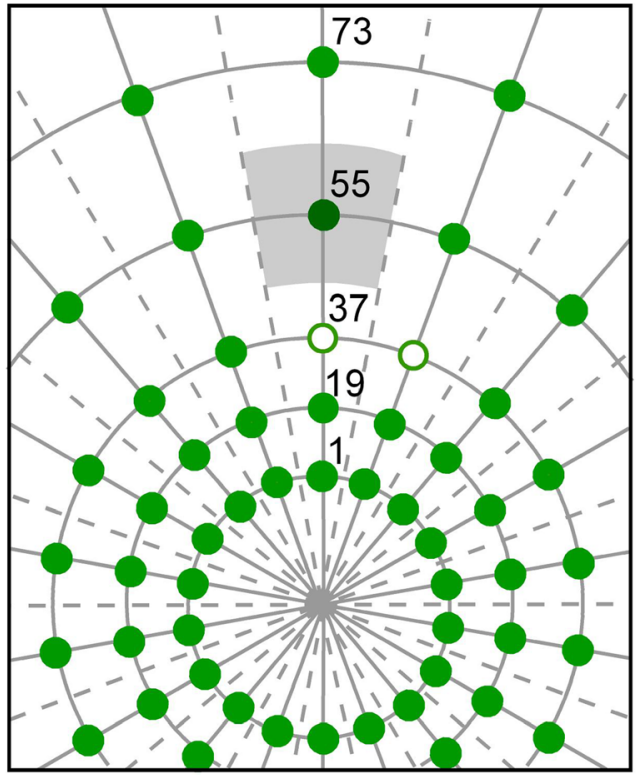

(b)

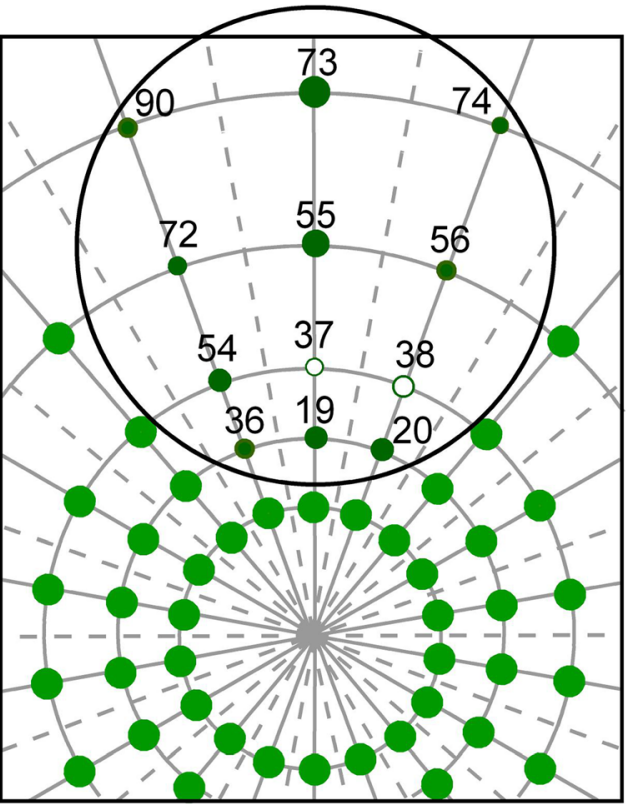

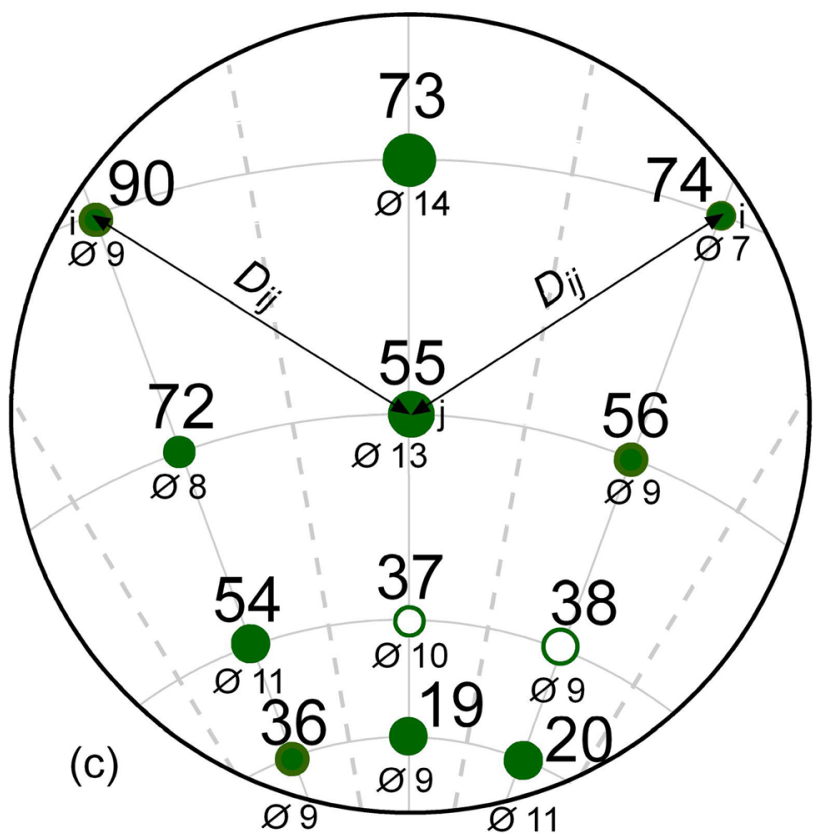

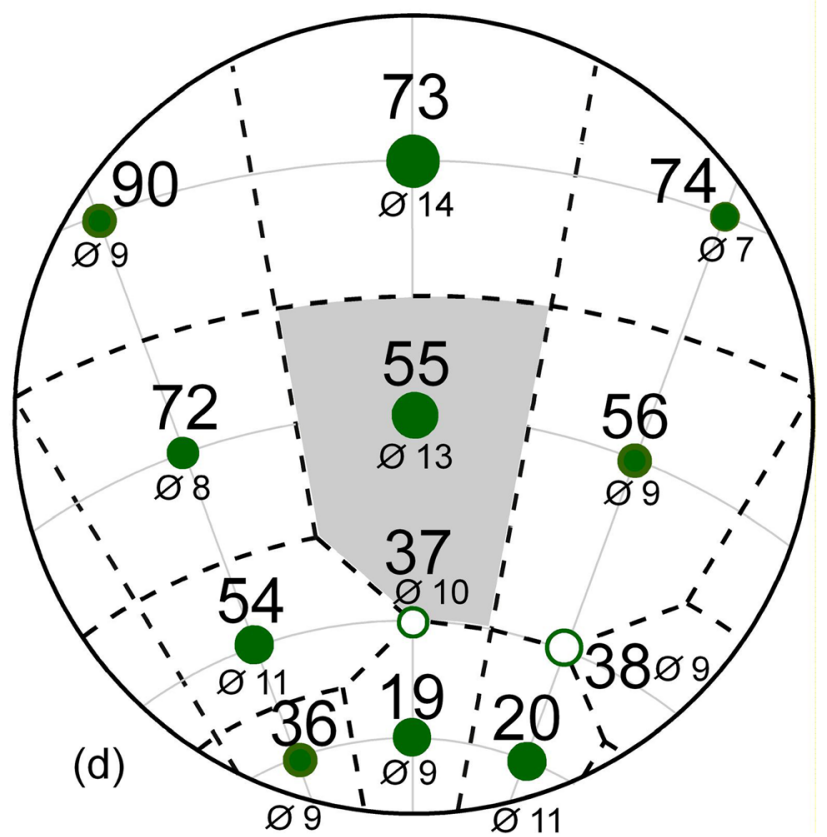

Fig. 3 Schematic excerpt from a Nelder wheel demonstrating different methods of calculating the competitive status of plants. a) growing space (grey area) defined by location on a certain spoke and circle; $\mathbf{b}$ ) distance-independent competition index: local stand density index (SD/); $\mathbf{c}$ ) distance dependent competition index according to Hegyi (1974) and d) growing space calculated by Voronoi polygons (Turner 2014). Large numbers: tree number, small numbers: tree diameter $(\mathrm{mm})$, black circle: search radius for competitors, empty symbols: previously dropped out trees, $D_{i j}$ : distance from centre tree to neighbouring tree

$$
\begin{aligned}
y_{i j}= & \beta_{0}+\beta_{1} \cdot \text { trial }_{651 i}+\beta_{2} \cdot \text { trial }_{653 i}+f_{1}\left(c i_{i j}, \text { trial }_{650 i}\right) \\
& +f_{2}\left(c i_{i j}, \text { trial }_{651 i}\right)+f_{3}\left(\text { ci }_{i j}, \text { trial }_{653 i}\right)+g\left(E_{i j}, N_{i j}\right)+\varepsilon_{i j}
\end{aligned}
$$

The indices $i$ and $j$ denominate tree $i$ on trial $j$. The variables trial $_{650}$, trial $_{651}$, and trial $_{653}$ are dummy variables, which are 1 for the trial they are named after and 0 in the other cases. The coefficients named $\beta$ are linear regression parameters, $c i$ is a competition index, either the local $S D I_{l}$ or the Hegyi-index as described above. $f_{1}, f_{2}$, and $f_{3}$ are nonparametric smoothers each one describing the influence of $c i$ on $y$ for each trial specifically. The smoother $g$ 
takes the position effect into account as explained above, and $\varepsilon$ represents i.i.d. errors. If not significant, linear terms were excluded and the model was re-fitted after that. The same approach was used for modelling increments of tree sizes $i y$, however, in addition to the previous model, tree size, expressed as tree volume $v$ was additionally included in form of trial-specific nonlinear smoothers.

$$
\begin{aligned}
i y_{i j}= & \beta_{0}+\beta_{1}\left(\text { trial }_{651 i}\right)+\beta_{2}\left(\text { trial }_{653 i}\right)+f_{1}\left(v_{i j}, \text { trial }_{650 i}\right) \\
& +f_{2}\left(v_{i j}, \text { trial }_{651 i}\right)+f_{3}\left(v_{i j}, \text { trial }_{653 i}\right) \\
& +f_{4}\left(c i_{i j}, \text { trial }_{650 i}\right)+f_{5}\left(\text { ci }_{i j}, \text { trial }_{651 i}\right) \\
& +f_{6}\left(\text { ciij }_{i j}, \text { trial }_{653 i}\right)+g\left(E_{i j}, N_{i j}\right)+\varepsilon_{i j}
\end{aligned}
$$

For analysing effects on tree allometry (research question 2), the same model (eq. 5) was applied. In this case, iy represents the allometric slopes of interest $\left(\alpha_{h, v}, \alpha_{d, v}, \alpha_{c l, v}, \alpha_{c s a, v}, \alpha_{c v, v}, \alpha_{h, d}\right)$. Again, the same model (eq. 5) was used for growing space efficiency as the dependent variables (research question 3). There, iy stands for eff $i_{i_{h}}$, eff ${i_{d}}_{i_{d}}$, eff $f_{i_{v}}$, eff $f_{i_{c l}}$, eff $f_{i_{\text {csa }}}$ and ef $f_{i_{c v}}$, respectively. For all statistical analyses, we used the software R (R Core Team 2014), and the R-package mgcv (Wood 2011) for regression analysis with GAMs.

\section{Results}

\section{Growth performance of trees since planting}

Since establishment, the oaks show a high variability in growth. These facts are valid within trials as well as between observed trial locations (Table 2). The range between minimum and maximum values of achieved tree dimensions is substantial. Taking into account that tree size was similar on trial level when planting trees are found with hardly any gain in dimension as well as trees with extensive expansion in size by the stage of the last survey. This tendency is similar on all trial plots although the time span of observation differs between four (SAN653) and seven years (GYO651). The differentiation of tree sizes also varies between trial locations. Here, ING650 shows the least range whereas GYO651 and SAN653 are much broader. Highest increment values (mean and maximum) concerning diameter, height, volume and crown dimensions are observed in SAN653.

The competition indices show a clear decreasing trend from the inner to the outer circle, as expected (Fig. 4). SDI and DCI behave similar. However, a substantial variation is obvious within circles indicating differing growing conditions for plants belonging to the same circle. In the following presentation of results, we use $D C I$ as competition index, but regressions using $S D I$ as independent variable show principally same results.
Applying eq. 4 revealed that only for $c v$ the intercept varies significantly between the trials (Table 3). For all other cases, $\beta_{1}$ and $\beta_{2}$ were removed from the model. For GYO651 all tested variables depend significantly from competition, this is not the case for ING650 and SAN653. Tree heights over competition show a unimodal optimum curve culminating in ING650 at smaller $D C I$ values and on smaller level (Fig. 5). The diameter decreases with accelerating tree density (Additional file 1: Figure S1, upper panel). Thus, taller heights are not reflected in tree volume so far (Additional file 1: Figure S1, lower panel). The same patterns are found for the shape of tree crowns (Additional file 2: Figure S2). Increasing density modulates crown shapes from short but broad to long but narrow profiles.

In case of $i v$ and $i c v$ the tree volume was used as a trial overarching effect in eq. 5 as differentiation between trials showed no significance. The overarching effect was significant in both cases (Table 4). In ING650 volume increment accelerated with increasing stand density. But oppositely, there was little effect of stand density on volume increment at GYO651 and SAN653, so far, denoting a decreasing trend by increasing density (Additional file 3: Figure S3, upper panel). It appears that there is a reverse trend between GYO651 and SAN653 concerning the effect of stand density on crown volume increment (Additional file 3: Figure S3, lower panel). This means, in relation with the findings concerning crown volume that smaller crowns have a higher crown volume increment in GYO651 but not yet in SAN653.

Local site effects may be caused by small-scale variation of soil properties or in micro climates. They show a relevant influence on the development of tree growth; $g(E, N)$ in eq. 4 and 5 is significant for all tested variables, except for tree volume increment (Tables 3 and 4). Figure 6 illustrates exemplarily the expression of the local side effects for ING650, GYO651 and SAN653. The darker the colour the more the variable is enhanced. Isolines separate areas with different conditions.

\section{Tree allometry variation}

The single-tree wise calculated allometric exponents (eq. 1) show a broad variation across the trials (Table 5, Fig. 7). For the exponents $\alpha_{h, w} \alpha_{d, w}, \alpha_{c l, w}$ and $\alpha_{h, d}$ the mode of their empirical distribution is remarkably near to the value predicted by the metabolic scaling theory. In case of $\alpha_{c s a, v}$ and $\alpha_{c v, v}$ the allometric exponent exceeds the theoretical value by far. There is a negative, almost linear correlation between the allometric exponents of tree height and tree diameter (Table 6). This means, volume increment is achieved by either height or diameter growth resulting in different tree shapes. A higher resource allocation into tree height also accelerates the development of the crown length $(r=0.4333)$. Vice versa, fostering 
Table 2 Tree characteristics of the trials ING650, GYO651 and SAN653 from the last survey

\begin{tabular}{|c|c|c|c|c|c|c|c|c|c|c|c|c|c|c|c|}
\hline Trial & $\begin{array}{l}\text { Year of } \\
\text { last survey }\end{array}$ & $\begin{array}{l}\text { Tree age } \\
\text { (yr) }\end{array}$ & & $\begin{array}{l}d \\
(\mathrm{~mm})\end{array}$ & $\begin{array}{l}h \\
(\mathrm{~cm})\end{array}$ & $\begin{array}{l}v \\
\left(\mathrm{dm}^{3}\right)\end{array}$ & $\begin{array}{l}\mathrm{cl} \\
(\mathrm{cm})\end{array}$ & $\begin{array}{l}c s a \\
\left(m^{2}\right)\end{array}$ & $\begin{array}{l}C V \\
\left(\mathrm{~m}^{3}\right)\end{array}$ & $\begin{array}{l}i_{d} \\
\left(\mathrm{~mm} \cdot \mathrm{yr}^{-1}\right)\end{array}$ & $\begin{array}{l}i_{h} \\
\left(\mathrm{~cm} \cdot \mathrm{yr}^{-1}\right)\end{array}$ & $\begin{array}{l}i_{V} \\
\left(\mathrm{dm}^{3} \cdot \mathrm{yr}^{-1}\right)\end{array}$ & $\begin{array}{l}i_{c l} \\
\left(\mathrm{~cm} \cdot \mathrm{yr}^{-1}\right)\end{array}$ & $\begin{array}{l}i_{c s a} \\
\left(\mathrm{~m}^{2} \cdot \mathrm{yr}^{-1}\right)\end{array}$ & $\begin{array}{l}i_{C V} \\
\left(\mathrm{~m}^{3} \cdot \mathrm{yr}^{-1}\right)\end{array}$ \\
\hline \multirow[t]{3}{*}{ ING650 } & 2012 & 6 & $\min$ & 4.0 & 32.0 & 0.002 & 0 & 0 & 0 & 1.0 & 8.0 & 0 & 0 & 0 & 0 \\
\hline & & & mean & 17.8 & 98.4 & 0.99 & 58.9 & 0.11 & 0.08 & 4.4 & 24.6 & 0.025 & 14.73 & 0.027 & 0.02 \\
\hline & & & $\max$ & 38.0 & 178.0 & 0.49 & 143.0 & 0.66 & 0.68 & 9.5 & 44.5 & 0.123 & 35.8 & 0.165 & 0.17 \\
\hline \multirow[t]{3}{*}{ GYO651 } & 2013 & 7 & $\min$ & 5.0 & 40.0 & 0.01 & 17.0 & 0.0004 & 0.002 & 1.3 & 10.0 & 0.02 & 4.3 & 0.00009 & 0.0005 \\
\hline & & & mean & 26.7 & 168.9 & 0.39 & 125.6 & 0.31 & 0.48 & 6.7 & 42.2 & 0.09 & 31.4 & 0.079 & 0.12 \\
\hline & & & $\max$ & 61.0 & 360.0 & 2.80 & 329.0 & 3.47 & 11.41 & 15.3 & 90.0 & 0.70 & 82.3 & 0.867 & 2.85 \\
\hline \multirow[t]{3}{*}{ SAN653 } & 2012 & 4 & $\min$ & 1.0 & 2.0 & 0 & 1.0 & 0.0005 & 0.00004 & 0.5 & 1.0 & 0.000 & 0.50 & 0.0003 & 0.00002 \\
\hline & & & mean & 24.3 & 81.1 & 0.15 & 78.9 & 0.37 & 0.32 & 12.2 & 40.5 & 0.08 & 39.5 & 0.185 & 0.16 \\
\hline & & & $\max$ & 58.00 & 210.0 & 1.85 & 205.0 & 2.72 & 3.02 & 29.0 & 105.0 & 0.93 & 102.5 & 1.360 & 1.51 \\
\hline
\end{tabular}

$d$ diameter at root collar, $h$ tree height, $v$ tree volume, $c l$ crown length, csa crown cross section area, $c v$ crown volume, $i$ annual increment since planting, 0 indicates values close to zero 

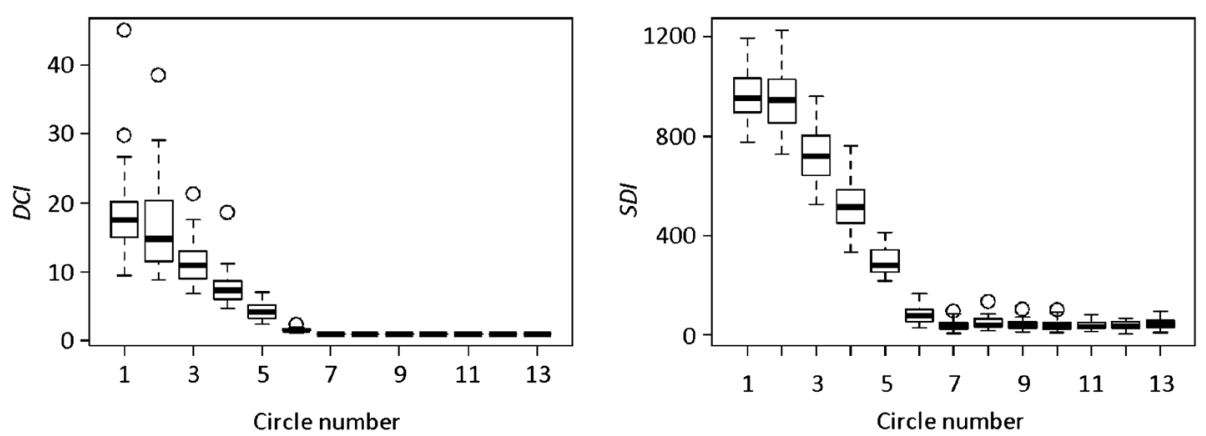

Fig. 4 Boxplot showing the variation of cis within the circles of the Nelder wheels for ING650 at last survey. DCI=Hegyi index, SDI=stand density index

diameter increment reduces investments into crown length $(r=-04335)$. At the same time, the allometric slope of crown cross section area is negatively correlated with $\alpha_{h, v}$ but positively correlated with $\alpha_{d, v}$. By this, crown shape seem to tend to either short but broad crowns or long but narrow crowns as already described above.

Again, the linear regression parameters $\beta_{1}$ and $\beta_{2}$ in eq. 5 had no significant effect on the model results and were thus removed from the regression. The values for the respective intercept (Table 7) reflect the mean values from Table 5. However, the allometric exponents are more or less modified by tree size and by stand density. In SAN653 only $\alpha_{h, d}$ is affected by competition. Higher levels of competition push trees to invest more into height when growing (Fig. 8) and to reduce the relative diameter feed (only significant for ING650) (Additional file 4: Figure S4) and in consequence to a higher $\alpha_{h, d}$ (Additional file 5: Figure S5). Also $\alpha_{c l, v}$ rose with accelerating competition showing a linear trend (Additional file 6: Figure S6). $\alpha_{c s a, v}$ is negatively affected by density (Additional file 7: Figure S7). Both relationships link to a reduced $\alpha_{c v, v}$ (Additional file 8: Figure S8). Also in case of the tested allometric exponents by eq. 5 , local effects summarized by the non-parametric smoother $g(E, N)$ showed a significant impact onto their expression (Table 7).

\section{Space use efficiency}

Only in case of the efficiencies, concerning tree diameter, crown length and crown projection area the intercept varied between the trials significantly. In all other cases, the trial effect was therefore not included into the general additive regression model (Table 8 ). The course of the smoothers for tree volume $\left(f_{1}-f_{3}\right)$ and competition $\left(f_{4}-f_{6}\right)$ in eq. 5 were significant in case of all variables (Table 8), but concerning eff $i_{i_{c v}}$ at ING650 the significance is only reached at the $p=0.1$ level. The spatial effect depicted by the term $g(E, N)$ appeared to be significant for the variables eff $f_{i_{h}}$, eff $f_{i_{c l}}$ and $e f f_{i_{c c}}$.

At the current young ontological stage, the oaks on the Nelder-trials showed clearly higher growth efficiency at higher stand densities. Available resources are turned into higher rates of productivity. Figure 9 (lower panels) depicts the trend for the effect of competition on height growth efficiency. Increasing density leads to an explicit uprating in efficiency. The curves showed an optimum at stand densities that are represented within the inner

Table 3 Regression parameters and level of significance for the smoothers for selected tree and crown dimensions according to eq. 4

\begin{tabular}{|c|c|c|c|c|c|c|c|c|c|c|c|c|c|c|c|c|c|c|}
\hline & \multicolumn{3}{|l|}{$h$} & \multicolumn{3}{|l|}{$d$} & \multicolumn{3}{|l|}{$v$} & \multicolumn{3}{|l|}{$\mathrm{cl}$} & \multicolumn{3}{|l|}{$\operatorname{csa}$} & \multicolumn{3}{|l|}{$\mathrm{CV}$} \\
\hline & Est. & Std. E. & p & Est. & Std. E. & p & Est. & Std. E. & p & Est. & Std. E. & $p$ & Est. & Std. E. & p & Est. & Std. E. & $p$ \\
\hline$\beta_{0}$ & 115.0 & 1.01 & $* * *$ & 22.82 & 0.18 & $* * *$ & 0.0002 & 0.00006 & $* * *$ & 87.29 & 1.01 & $* * *$ & 0.26 & 0.007 & $* * *$ & -0.17 & 0.31 & \\
\hline$\beta_{1}(651)$ & - & - & - & - & - & - & - & - & - & - & - & - & - & - & - & 1.13 & 0.53 & * \\
\hline$\beta_{2}(653)$ & - & - & - & - & - & - & - & - & - & - & - & - & - & - & - & 0.26 & 0.50 & \\
\hline$f_{1}(D C l, 650)$ & & & $* * *$ & & & $* * *$ & & & & & & $* * *$ & & & & & & \\
\hline$f_{2}(D C l, 651)$ & & & $* * *$ & & & $* * *$ & & & $* * *$ & & & $* * *$ & & & $* * *$ & & & $* * *$ \\
\hline$f_{3}(D C l, 653)$ & & & & & & $* * *$ & & & $* * *$ & & & & & & $* * *$ & & & $* * *$ \\
\hline$g(E, N)$ & & & $* * *$ & & & $* * *$ & & & $* * *$ & & & $* * *$ & & & $* * *$ & & & $* *$ \\
\hline
\end{tabular}



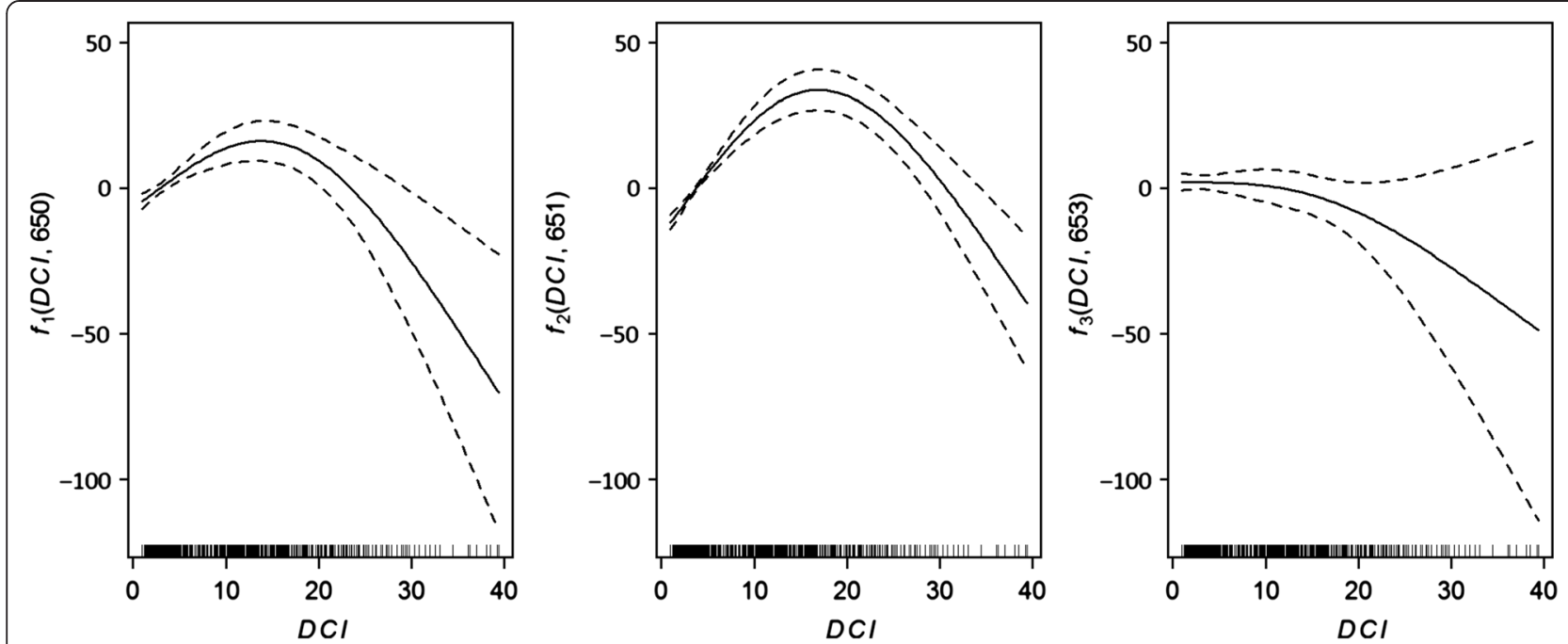

Fig. 5 Graphical illustration of the non-linear smoothers $f_{1}-f_{3}$ from eq. 4 for tree height as the dependent variable. Straight line: estimate, dashed lines: $95 \%$ confidence area; $\mathrm{DCl}=$ Hegyi-index

circles of the trials. On ING650 and SAN653 the maximum effect value was reached at lesser competition level than in GYO651 (cf. the value of the smoother on $y$-axis). Space use efficiency was also accelerated with increasing tree volume (Fig. 9, upper panels). The progression of the curve is taking an asymptotic course bearing comparisons with diminishing marginal utility. The scales of the $y$-axis reveal that tree size had a smaller effect level compared to competition.

The described characteristics concerning the effect trend of density and tree size were valid for all analysed growth efficiencies. Additional file 9: Figure S9, Additional file 10: Figure S10, Additional file 11: Figure S11, Additional file 12: Figure S12, Additional file 13: Figure S13 illustrate the curve progression for the growth efficiencies concerning diameter, tree volume and crown dimensions.

Table 4 Regression parameters and level of significance for the smoothers for selected increment parameters according to eq. 5

\begin{tabular}{|c|c|c|c|c|c|c|}
\hline & \multicolumn{3}{|l|}{$i_{v}$} & \multicolumn{3}{|l|}{$i_{c V}$} \\
\hline & Est. & Std. E. & $p$ & Est. & Std. E. & $P$ \\
\hline$\beta_{0}$ & -0.00001 & 0.000002 & $* * *$ & -0.002 & 0.001 & \\
\hline$\beta_{1}(651)$ & 0.00002 & 0.000003 & $* * *$ & - & & \\
\hline$\beta_{2}(653)$ & 0.00001 & 0.000003 & $* * *$ & - & & \\
\hline$\beta_{3}(v)$ & -0.87 & 0.006 & $* * *$ & 533.86 & 30.36 & $* * *$ \\
\hline$f_{1}(D C l, 650)$ & & & $* * *$ & & & \\
\hline$f_{2}(D C l, 651)$ & & & * & & & * \\
\hline$f_{3}(D C l, 653)$ & & & $* * *$ & & & $* * *$ \\
\hline$g(E, N)$ & & & & & & $* * *$ \\
\hline
\end{tabular}

. $p$-value $<0.1,{ }^{*} p$-value $<0.05,{ }^{* *} p$-value $<0.01,{ }^{* * *} p$-value $<0.001, v$ was used as trial overarching linear effect. Non-linearity and trial separated usage showed no significance

\section{Discussion}

Turning Nelder-trials into single tree experiments

The classical evaluation routines for estimating growing space dependent growth and growth efficiency described by Nelder (1962) concern mostly annual or at maximum biennial plants. Thus, natural mortality hardly occurs during the trials' lifetime and can be neglected. Having long living tree species under focus within Nelder wheels at least in parts with higher density competition will cause dropouts of plants after a few years. Missing trees will change the current situation of competition of neighbouring trees and their provision with ground related resources and light. Using the growing space of a plant as it is defined by its position on a certain circle might bias the real resource supply, as missing trees do not affect it. Using competition indices instead of the approximated growing space better reflects the growing situation in terms of resource supply. In particular, changes of the respective growing situation in time can be retraced. By this, the stand related analyses shift into a single tree focussed approach.

An advantage of Nelder trials is that they embrace by relative small space requirements a broad range of stand densities, which can hardly be realised by classical yield experiments. Here, extreme high and low stand densities were often left out. However, these are most important in understanding the mechanisms that link resource supply and growth behaviour of trees. We presented results using the Hegyi-index as indicator for competition likewise used by Vanclay et al. (2013). But we also tested the local $S D I$, which is more useful when upscaling stand densities to hectare level.

Our approach, using GAM regression models for single-tree focussed Nelder-wheel evaluations proved to 


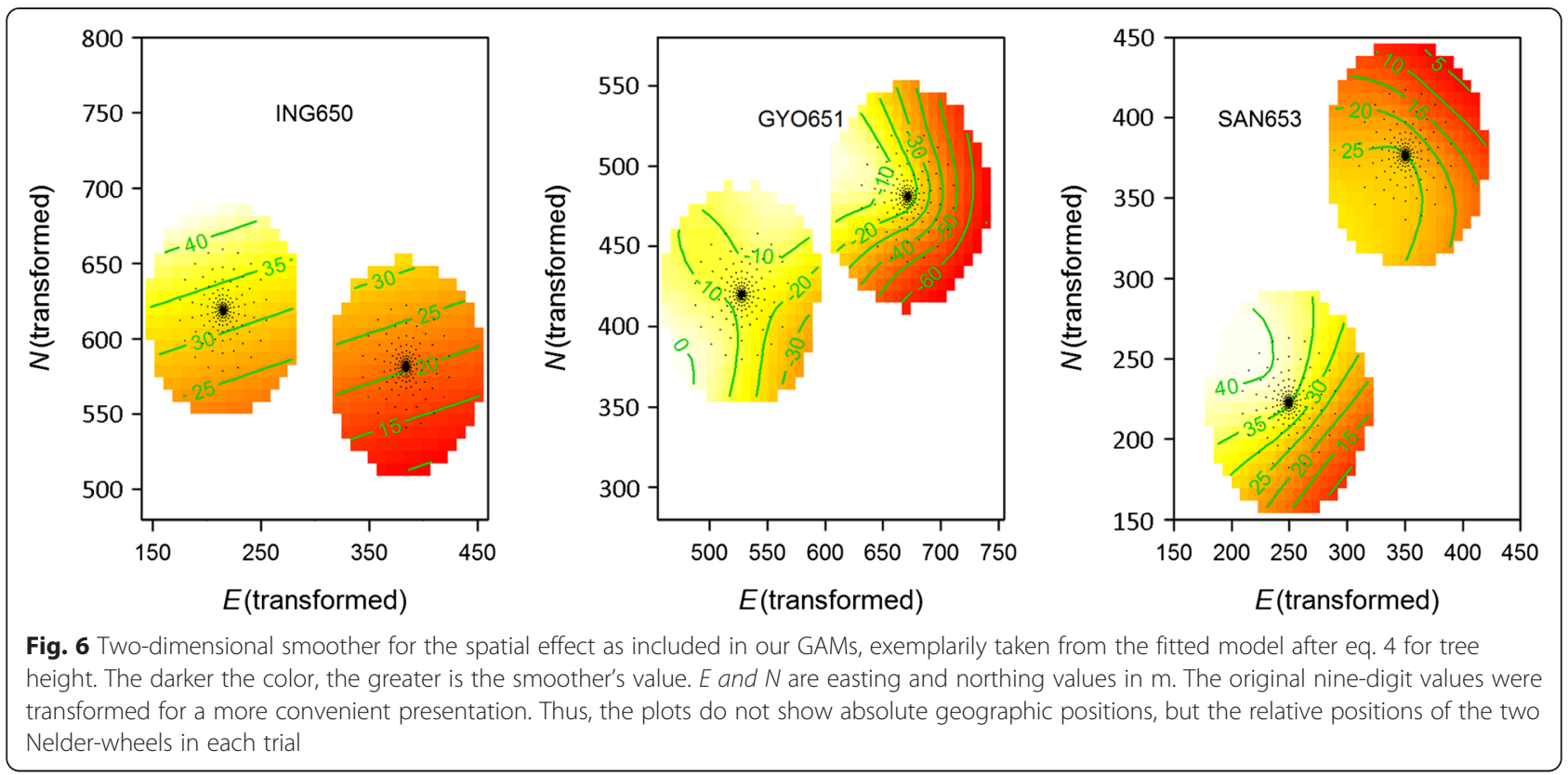

be robust and revealing. Especially, including unmeasured and unmeasurable position effects by a two-dimensional nonparametric smoother turned out to be straightforward and easy-to-apply way to avoid undesired autocorrelation effects in the statistics; it does not require assumptions like isotropy and homogeneity of spatial autocorrelation. Furthermore, this approach may also be helpful for identifying microsite variations at the study sites.

\section{Empirical evidence for testing and further development of ecological theory}

Relationship between stand density and growth

The Nelder design is suitable for revelation of the species-specific relationship between stand density and growth. The ratio between the individual plant growth (e.g. periodic mean growth of basal area or volume) and the respective growing area results in tree productivity in terms of growth per year and unit area. Suppose, the trees represent the mean tree development this

Table 5 Across-trial distribution properties of the single-tree allometric exponents

\begin{tabular}{lcccccc}
\hline & $a_{h, v}$ & $a_{d, v}$ & $a_{c l, v}$ & $a_{c s a, v}$ & $a_{c v, v}$ & $a_{h, d}$ \\
\hline $\mathrm{N}$ & 1299 & 1298 & 1284 & 1248 & 1260 & 1159 \\
Min & -0.46 & 0.08 & -1.36 & -1.51 & -1.40 & 0.01 \\
Mean & 0.22 & 0.39 & 0.41 & 1.43 & 1.85 & 0.70 \\
Mode & 0.24 & 0.38 & 0.26 & 1.22 & 1.59 & 0.50 \\
Max & 0.87 & 0.73 & 2.11 & 4.44 & 5.34 & 0.98 \\
Sd & 0.16 & 0.08 & 0.42 & 0.77 & 0.87 & 0.46 \\
MST & $1 / 4$ & $3 / 8$ & $1 / 4$ & $1 / 2$ & $3 / 4$ & $2 / 3$ \\
\hline
\end{tabular}

MST metabolic scaling theory productivity equals the stand productivity for the given stand density. The productivity is of interest for plant ecology as it reflects how efficient the plant uses the available resource in terms of growing area for growing (Webster and Lorimer 2003; Pretzsch and Schütze 2005) and it is of interest for production economy as it reveals the relationship between stand density and yield (Sterba 1999).

Of special interest is which stand density enables maximum productivity per unit area. A question that has intrigued forestry science from its beginning is whether stand volume production is at a maximum in untreated self-thinning stands, or whether silvicultural thinning can raise it. Until present mainly the two different concepts are discussed: Curtis et al. (1997) and Zeide (2001, 2002) assumed that the density-growth curve is asymptotic as maximum growth occurs in untreated (maximum stocked) stands. Among others, Assmann (1970) and Pretzsch (2005) provided evidence that the density-growth curve can be a unimodal or optimum curve where maximum growth is reached at belowmaximum densities.

Most of the contradictory findings result from middle-aged stands, while respective studies about the density-growth relationships during the early and especially during the initial stand phase are missing. However, these are relevant for understanding the later stand dynamics. In addition, they are relevant for forest practitioner for choosing the most appropriate and productive initial stand density. Nelder trials pave the way to close this knowledge gap. Results from the first measurements of the presented Nelder trials support the concept that density-growth relates with an optimum curve. 

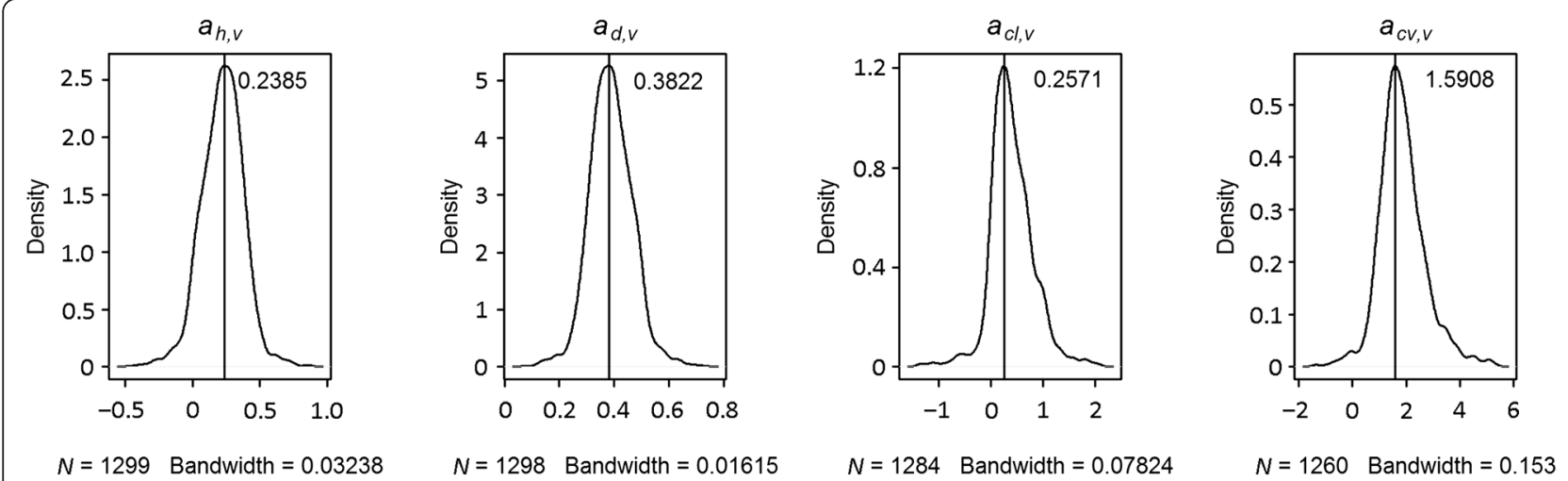

Fig. 7 Selected empirical density curves for the allometric exponents $a_{h, v,} a_{d, v,} a_{c l, v}$ and $a_{c v, v}$. The numbers inside the diagrams quantify the distributions' mode

\section{Interaction between competition and facilitation in the context of the stress-gradient hypothesis}

The presented extended Nelder design may reveal whether facilitation between neighboring trees occur rather on poor sites while competition is more relevant on rich sites, as predicted by the stress-gradient hypothesis, SGH (Callaway and Walker 1997). So far, empirical evidence of this behavior is mostly based on herbaceous plants growing rather solitarily on sites providing conditions that are not suitable for trees to establish or persist. Extension to forest stands and higher densities may contribute to ecological theory but also provide valuable knowledge for forest practice. The interplay between facilitation and competition on different sites may affect the choice of the planting density, thinning regime, and stand density regulation in view of climate change.

Both, living in association or solitary bears pros and cons in terms of growth. An individual tree may be facilitated, e.g. physically by neighbours as they protect against stormbreakage (von Lüpke and Spellmann 1997; 1999), sun scorch of bark (Assmann 1970), or snow sliding (Kuoch 1972; Mayer and Ott 1991, pp 194-197). However, neighbourhood is ambivalent as it also means competition when there are not sufficient resources for all (Connell 1990). The interplay of facilitation and competition and it's net effect determine the growth and coexistence of trees.

Table 6 Correlation matrix of selected allometric exponents

\begin{tabular}{|c|c|c|c|c|c|}
\hline & $a_{h, v}$ & $a_{d, v}$ & $a_{c l, v}$ & $a_{c s a, v}$ & $a_{c V, v}$ \\
\hline$a_{h, v}$ & 1 & $-0.99 * * *$ & $0.43^{* * *}$ & $-0.20^{* * *}$ & 0.02 \\
\hline$a_{d, v}$ & & 1 & $-0.43^{* * *}$ & $0.20^{* * *}$ & -0.02 \\
\hline$a_{c l, v}$ & & & 1 & -0.05 & $0.43^{* * *}$ \\
\hline$a_{C s a, v}$ & & & & 1 & $0.88^{* * *}$ \\
\hline$a_{C V, V}$ & & & & & 1 \\
\hline
\end{tabular}

As the extended Nelder design observes tree growth reactions along both a gradient of competition (in terms of tree stand area) and a gradient of environmental conditions (from mild atlantic climate to temperate, and to rather harsh continental climate) it may contribute to understanding how the balance between facilitation and competition is modified by the prevailing site conditions. During the first years of observation on our Nelder trials, we observed a different behavior of tree growth dynamics between the trial locations. In ING650 and GYO651, facilitation seems to foster at least height growth. Up to now, there is no significant differentiation in height by density in SAN653, having best growing conditions form all three mentioned trials. However, the time of observation could be here too short to connect this fact with site conditions. Subsequent observation of various aspects of tree growth (e.g. tree height, volume, biomass, leaf structure) in dependence on both site conditions and stand density may advance the SGH towards applicability to forest ecosystems (Forrester 2013). Thus, the presented Nelder may counteract the present deficit of empirical evidence.

\section{Variability and covariation between allometric relationships as prerequisite for the individual plants plasticity and competitiveness}

The metabolic scaling theory (MST) provides a promising synthesis for the functioning and structure of plants from organ to ecosystem level (West et al. 1997; Enquist et al. 1998). The mainstay of MST, the scaling between leaf mass, $\mathrm{ml}$, and total plant biomass, $\mathrm{mt}$, is widely held to follow the $3 / 4$ power scaling rule $m l \propto m t^{3 / 4}$ (Niklas 2004; Price et al. 2010). However, allometric scaling appears to be dependent on species (Purves et al. 2007; Pretzsch and Dieler 2012), the species combination in mixed stands (Dieler and Pretzsch 2013), as well as from the trees' local competitive constellation (Mäkelä and Valentine 2006; Duursma et al. 2010). 
Table 7 Regression parameters and level of significance for the smoothers for allometric exponents resulting from eq. 5

\begin{tabular}{|c|c|c|c|c|c|c|c|c|c|c|c|c|c|c|c|c|c|c|}
\hline & \multicolumn{3}{|l|}{$a_{h, v}$} & \multicolumn{3}{|l|}{$a_{d, v}$} & \multicolumn{3}{|l|}{$a_{c l, V}$} & \multicolumn{3}{|l|}{$a_{c s a, v}$} & \multicolumn{3}{|l|}{$a_{C V, V}$} & \multicolumn{3}{|l|}{$a_{h, d}$} \\
\hline & Est. & Std. E. & $p$ & Est. & Std. E. & $p$ & Est. & Std. E. & $p$ & Est. & Std. E. & $p$ & Est. & Std. E. & $p$ & Est. & Std. E. & $p$ \\
\hline$\beta_{0}$ & 0.22 & 0.005 & $* * *$ & 0.39 & 0.003 & $* * *$ & 0.39 & 0.01 & $* * *$ & 1.43 & 0.03 & $* * *$ & 1.84 & 0.03 & $* * *$ & 0.66 & 0.02 & $* * *$ \\
\hline$\beta_{0}(651)$ & - & - & & - & - & & - & - & & - & - & & - & - & & - & - & \\
\hline$\beta_{0}(653)$ & - & - & & - & - & & - & - & . & - & - & & - & - & & - & - & \\
\hline$f_{1}(v, 650)$ & & & & & & & & & * & & & $* *$ & & & * & & & \\
\hline$f_{2}(v, 651)$ & & & $* * *$ & & & $* * *$ & & & & & & & & & & & & $* * *$ \\
\hline$f_{3}(v, 653)$ & & & * & & & * & & & $* *$ & & & & & & & & & * \\
\hline$f_{4}(D C l, 650)$ & & & $* * *$ & & & $* * *$ & & & . & & & $* * *$ & & & * & & & $* * *$ \\
\hline$f_{5}(D C l, 651)$ & & & $* * *$ & & & & & & $*$ & & & $* * *$ & & & $* * *$ & & & $* * *$ \\
\hline$f_{6}(D C l, 653)$ & & & & & & & & & & & & & & & & & & $* * *$ \\
\hline$g(E, N)$ & & & $* * *$ & & & $* * *$ & & & $* * *$ & & & $* * *$ & & & $* * *$ & & & $* *$ \\
\hline
\end{tabular}

. $p$-value $<0.1,{ }^{*} p$-value $<0.05,{ }^{* *} p$-value $<0.01,{ }^{* * *} p$-value $<0.001$

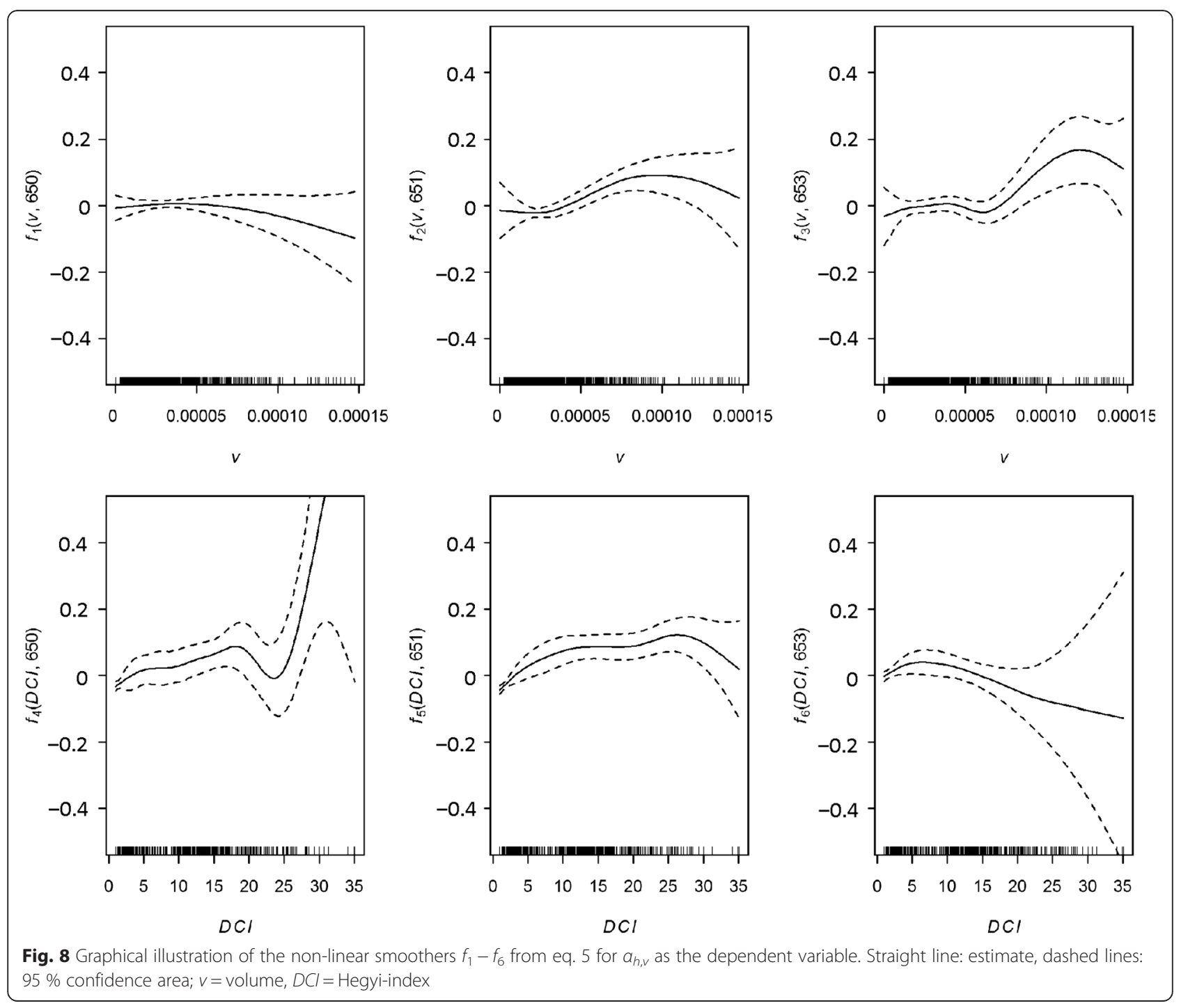


Table 8 Regression parameters and level of significance for the smoothers for growth efficiencies according to eq. 5

\begin{tabular}{|c|c|c|c|c|c|c|c|c|c|c|c|c|c|c|c|c|c|c|}
\hline & eff $f_{i_{h}}$ & & & $e f f_{i_{d}}$ & & & eff $f_{i_{v}}$ & & & $\underline{e f f_{i_{c l}}}$ & & & eff $i_{i_{s a}}$ & & & $\underline{e f f_{i_{c v}}}$ & & \\
\hline & Est. & Std. E. & $p$ & Est. & Std. E. & $p$ & Est. & Std. E. & $p$ & Est. & Std. E. & $p$ & Est. & Std. E. & $p$ & Est. & Std. E. & $p$ \\
\hline$\beta_{0}$ & 76.26 & 2.20 & $* * *$ & 10.20 & 1.36 & $* * *$ & 0.0001 & 0.000007 & $* * *$ & 48.26 & 7.15 & $* * *$ & 0.08 & 0.03 & * & 0.10 & 0.008 & $* * *$ \\
\hline$\beta_{0}(651)$ & - & - & & -2.39 & 2.10 & & - & - & & -2.29 & 11.16 & & -0.02 & 0.05 & & - & - & \\
\hline$\beta_{0}(653)$ & - & - & & 14.40 & 2.03 & $* * *$ & - & - & & 35.41 & 10.77 & $* *$ & 0.12 & 0.05 & * & - & - & \\
\hline$f_{1}(\mathrm{vol}, 650)$ & & & $* * *$ & & & $* * *$ & & & $*$ & & & $* * *$ & & & $*$ & & & . \\
\hline$f_{1}(\mathrm{vol}, 651)$ & & & $* * *$ & & & $* * *$ & & & $* * *$ & & & $* *$ & & & $* * *$ & & & $* * *$ \\
\hline$f_{1}(\mathrm{vol}, 653)$ & & & $*$ & & & $* * *$ & & & * & & & $* * *$ & & & $* * *$ & & & $* * *$ \\
\hline$f_{2}(D C l, 650)$ & & & $* * *$ & & & $* * *$ & & & $* * *$ & & & $* * *$ & & & $* * *$ & & & $* * *$ \\
\hline$f_{2}(D C l, 651)$ & & & $* * *$ & & & $* * *$ & & & $* * *$ & & & $* * *$ & & & $* * *$ & & & $* * *$ \\
\hline$f_{2}(D C l, 653)$ & & & $* * *$ & & & $* * *$ & & & $* * *$ & & & $* * *$ & & & $* * *$ & & & $* * *$ \\
\hline$g(E, N)$ & & & $* * *$ & & & & & & . & & & $*$ & & & & & & $* * *$ \\
\hline
\end{tabular}

. $p$-value $<0.1,{ }^{*} p$-value $<0.05,{ }^{* *} p$-value $<0.01,{ }^{* * *} p$-value $<0.001$
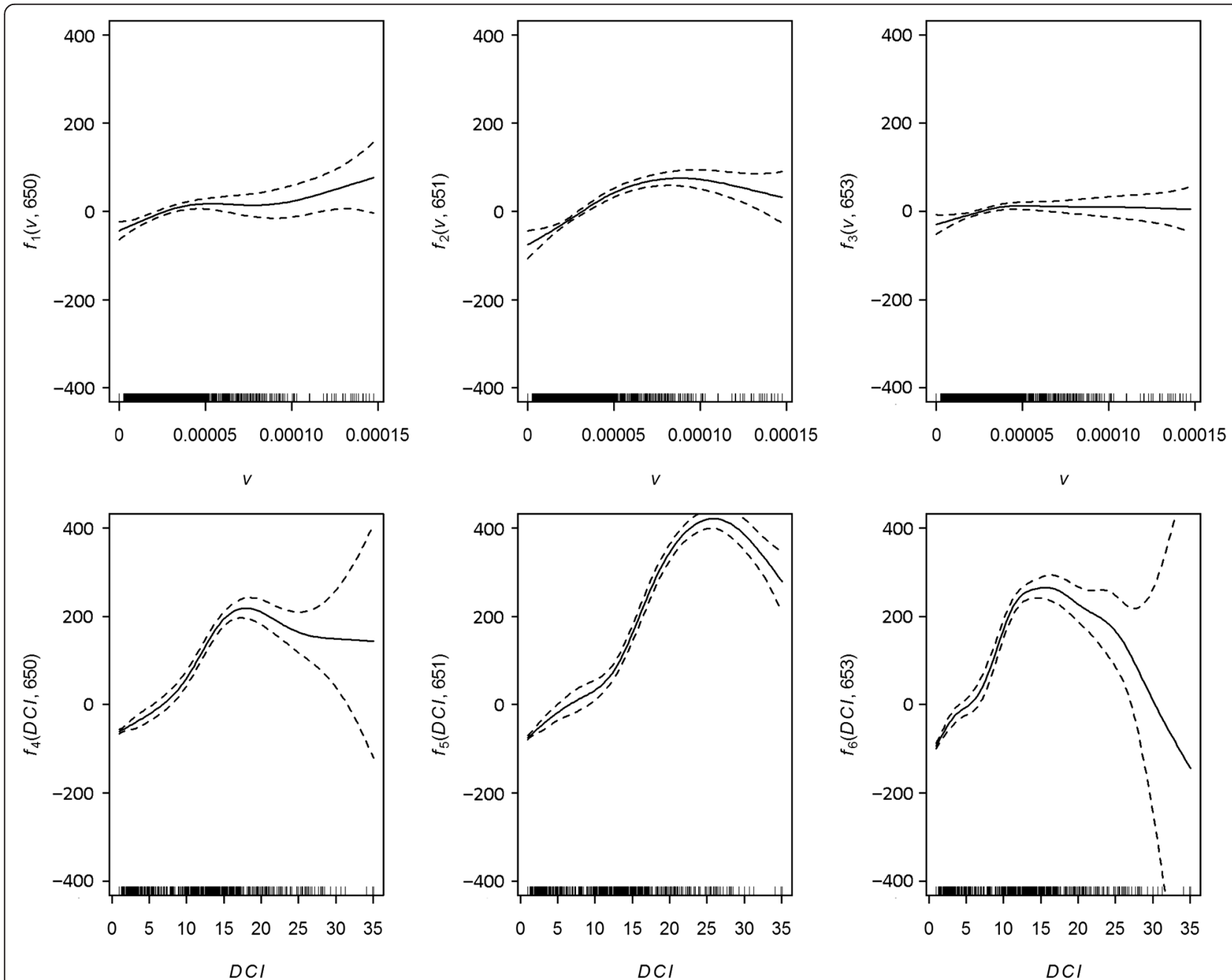

Fig. 9 Graphical illustration of the non-linear smoothers $f_{1}-f_{6}$ from eq. 5 for eff $f_{h}$ as the dependent variable. Straight line: estimate, dashed lines: $95 \%$ confidence area; $v$ = volume, $\mathrm{DCl}=$ Hegyi-index 
Here, we consider the MST as a first-order relationship for the form development of plants and use it as a reference and starting point. However, we further explored it as suggested by Price et al. (2010) based on the Nelder plots in oak.

The trees in the centre of the Nelder wheels represent dense stand and self-thinning conditions, which are mostly used for allometric analysis. Those trees rather follow in most of their allometry attributes the allometry predicted by MST. With increasing distance from the centre and approach to the periphery competition and facilitation squeeze or stretch the crown and cause a broad intra-specific variation in scaling of structure. Because of the wide range of competitive constellations on the Nelder plots the structural scaling of the trees showed also a wide intra-specific variation (Fig. 7). Table 6 revealed positive as well as negative correlation between different scaling exponents of structure, e.g. between $\alpha_{h, v}, \alpha_{c s a, v}$, and $\alpha_{c v, v}$. The assumed stable metabolic scaling and revealed variable scaling of crown structure are not necessarily a contradiction. It is rather this variability of the crown, which provides a plastic holding structure for the leaf organs and enables the plant to keep close to the $3 / 4$ power leaf mass-plant biomass trajectory.

We demonstrate this thought by the scaling relations between tree volume, $v$, and the crown characteristics crown length, $c l$, and crown cross section area, $c s a,\left(c l \propto \nu^{\left(\alpha_{c l, v}\right)}, c s a^{\propto} v^{\left(\alpha_{c s a, v}\right)}\right)$. As crown volume is the product of crown length and crown cross section area $(c v=c l * c s a)$, this results in $c v^{\propto} v^{\left(\alpha_{c l, v}+\alpha_{c a, v}\right)}$ and shows that $\alpha_{c v, v}=\alpha_{c l, v}+\alpha_{c s a, v}$.

MST assumes common scaling relationships for allometric ideal plants, e. g. $\alpha_{c l, v}=1 / 4, \alpha_{c s a, v}=1 / 2$, and as basic assumption according to West et al. (2009) $\alpha_{c v, v}=3 / 4$. Insertion of the general scaling exponents for an allometric ideal plant into $\alpha_{c v, v}=\alpha_{c l, v}+\alpha_{c s a, v}$ yields $\quad \alpha_{c v, v}=(1 / 4+1 / 2)=3 / 4$. However, $\quad \alpha_{c v, v}=3 / 4$ could also result from diverging components, e. g. $\alpha_{c v, v}=(1 / 8+5 / 8)=3 / 4$. In the latter case, there is a trade-off between both scaling exponents. Crown width might increase on the expense of crown length, but the combination of both keeps the scaling of the crown volume rather stable.

According to that, morphological variability is even a requirement for holding trees on a rather stable leaf massplant mass or root mass-plant mass trajectory even under variable or changing environmental conditions. We found an intra-specific correlation between the structural scaling exponents which does not keep $\alpha_{c v, v}$ constant at 3/4 but stabilizes it in a quite narrow corridor around $3 / 4$. In view of this variability, scaling of the allometric ideal plant may be of benefit when using it as reference but is somewhat of a phantom when trying to find it.
Successive surveys will explore the temporal variability of the crown allometry. Additional biomass analysis of above and below ground biomass on reserve partial wheels in close vicinity to the main plots will extend the allometric analyses to the root-shoot allometry and deliver total shoot mass, plant mass, and specific wood density, while present evaluations are based on tree volume as substitute variable.

\section{Conclusions}

The presented methods for analysing Nelder trials pave the way to make the experimental design attractive for forest science. The possibility to represent a wide spread of stand densities and respectively growing condition within one trial with relative little demand for space improves long-term studies in forest ecology. Single tree based analyses are more and more essential to understand the multiform interactions and their possible variation with growing conditions between trees in complex ecosystems. Thus, Nelder trials help to strengthen the development of ecological theory and provide simultaneously relevant results for forest management. The investigation of Nelder trial is not restricted to issues concerning growth dynamics. Aspects of e.g. above and below ground biodiversity and $\mathrm{CO}_{2}$ balancing of ecosystems can be linked to stand dynamics at different stand densities.

\section{Additional files}

Additional file 1: Figure S1. Graphical illustration of the non-linear smoothers $f_{1}-f_{3}$ from eq. 4 for tree diameter (upper panel) and tree volume (lower panel) as the dependent variable. Straight line: estimate, dashed lines: $95 \%$ confidence area; DCl= Hegyi-index.

Additional file 2: Figure S2. Graphical illustration of the non-linear smoothers $f_{1}-f_{3}$ from eq. 4 for crown length (upper panel), crown cross section area (middle panel), and crown volume (lower panel) as the dependent variable. Straight line: estimate, dashed lines: 95 \% confidence area; $D C l=$ Hegyi-index.

Additional file 3: Figure S3. Graphical illustration of the non-linear smoothers $f_{1}-f_{3}$ from eq. 4 for tree volume increment (upper panel), and crown volume increment (lower panel) as the dependent variable. Straight line: estimate, dashed lines: $95 \%$ confidence area; DCl= Hegyi-index.

Additional file 4: Figure S4. Graphical illustration of the non-linear smoothers $f_{1}-f_{6}$ from eq. 5 for $a_{d, v}$ as the dependent variable. Straight line: estimate, dashed lines: 95 \% confidence area; $v=$ volume, $D C l=$ Hegyi-index

Additional file 5: Figure S5. Graphical illustration of the non-linear smoothers $f_{1}-f_{6}$ from eq. 5 for $a_{h, d}$ as the dependent variable. Straight line: estimate, dashed lines: $95 \%$ confidence area; $v=$ volume, $D C l=$ Hegyi-index.

Additional file 6: Figure S6. Graphical illustration of the non-linear smoothers $f_{1}-f_{6}$ from eq. 5 for $a_{c l, v}$ as the dependent variable. Straight line: estimate, dashed lines: $95 \%$ confidence area; $v=$ volume, $D C l=$ Hegyi-index

Additional file 7: Figure S7. Graphical illustration of the non-linear smoothers $f_{1}-f_{6}$ from eq. 5 for $a_{c s a, v}$ as the dependent variable. Straight line: estimate, dashed lines: $95 \%$ confidence area; $v=$ volume, $D C l=$ Hegyi-index . 
Additional file 8: Figure S8. Graphical illustration of the non-linear smoothers $f_{1}-f_{6}$ from eq. 5 for $a_{c y, v}$ as the dependent variable. Straight line: estimate, dashed lines: $95 \%$ confidence area; $v=$ volume,

$D C l=$ Hegyi-index

Additional file 9: Figure S9. Graphical illustration of the non-linear smoothers $f_{1}-f_{6}$ from eq. 5 for eff $f_{i_{\alpha}}$ as the dependent variable. Straight line: estimate, dashed lines: $95 \%$ confidence area; $v=$ volume, $D C l=$ Hegyi-index

Additional file 10: Figure S10. Graphical illustration of the non-linear smoothers $f_{1}-f_{6}$ from eq. 5 for eff $f_{i v}$ as the dependent variable. Straight line: estimate, dashed lines: $95 \%$ confidence area; $v=$ volume, $\mathrm{DCl}=$ Hegyi-index

Additional file 11: Figure S11. Graphical illustration of the non-linear smoothers $f_{1}-f_{6}$ from eq. 5 for eff $_{i_{c}}$ as the dependent variable. Straight line: estimate, dashed lines: $95 \%$ confidence area; $v=$ volume,

$D C l=$ Hegyi-index

Additional file 12: Figure S12. Graphical illustration of the non-linear smoothers $f_{1}-f_{6}$ from eq. 5 for eff $f_{\text {ces }}$ as the dependent variable. Straight line: estimate, dashed lines: $95 \%$ confidence area; $v=$ volume, $D C l=$ Hegyi-index .

Additional file 13: Figure S13. Graphical illustration of the non-linear smoothers $f_{1}-f_{6}$ from eq. 5 for eff $f_{i_{c}}$ as the dependent variable. Straight line: estimate, dashed lines: $95 \%$ confidence area; $v=$ volume, $\mathrm{DCl}=$ Hegyi-index

\section{Competing interests}

The authors declare that they have no competing interests.

\section{Authors' contributions}

EU developed the trial design, analysed and interpreted the data, and wrote the manuscript. PB designed the statistical methods and wrote the manuscript. MU collected data, cross checked the data and supported analyses. $\mathrm{MH}$ developed analysis routines, and proof read the manuscript. TH implemented trials in Hungary, collected data and proof read the manuscript. FL and JG supported the strategy of analyses and wrote the manuscript. LS implemented the Nelder trials in situ, maintains the plots and collected data. GT supported the strategy of analyses and wrote the manuscript. MV implemented the trials in Italy, collected data and proof read the manuscript. HP initiated the trial series and the manuscript, interpreted the results and wrote the manuscript. All authors read and approved the final manuscript

\section{Acknowledgements}

We thank AUDI AG, Automobili Lamborghini S.P.A., AUDI HUNGARIA MOTOR Kft. and AUDI BBRUSSELS for supporting the establishment of the Nelder trial series. We also thank AUDI Stiftung für Umwelt for funding the project "Biodiversity, productivity, and C-sequestration of oak stands" (No. 5102150). We further wish to thank the Bavarian State Ministry for Nutrition, Agriculture and Forestry for permanent support of the project W 07 "Long-term experimental plots for forest growth and yield research" (7831-23953-2014). The included trials are located on areas under responsibility of different forest administrations. We are deeply grateful to the respective sponsoring forest administrations. Thanks are also due to Ulrich Kern for the graphical artwork and two anonymous reviewers for their thoroughly criticism.

\section{Author details}

'School of Life Sciences Weihenstephan, Technische Universitaet Muenchen, Hans-Carl-von-Carlowitz-Platz 2, 85354 Freising, Germany. ${ }^{2}$ University of West Hungary, Faculty of Forestry, Ady E. u. 5, Sopron 9400, Hungary. ${ }^{3}$ Faculty of Science and Technology, Freie Universität Bozen, Universitaetsplatz 5, Bolzano 39100, Italy.

Received: 27 December 2014 Accepted: 13 May 2015

Published online: 27 May 2015

\section{References}

Assmann E (1970) The principles of forest yield study. Pergamon Press, Oxford, New York
Biging GS, Dobbertin M (1992) A comparison of distance-dependent competition measures for height and basal area growth of individual conifer trees. For Sci 38(3):695-720

Biging GS, Dobbertin M (1995) Evaluation of competition indices in individual tree growth models. For Sci 41(2):360-377

Callaway RM, Walker LR (1997) Competition and facilitation: a synthetic approach to interactions in plant communities. Ecology 78(7):1958-1965

Connell JH (1990) Apparent versus "real" competition in plants. In: Grace JB, Tilman D (eds) Perspectives on plant competition. Academic press, INC., Harcourt Brace Jovanovich, Publishers, San Diego

R Core Team (2014) R: A language and environment for statistical computing. $R$ Foundation for Statistical Computing, Vienna, Austria. http://www.R-project.org/. Accessed 15 Oct 2014

Curtis RO, Marshall DD, Bell JF (1997) LOGS. A pioneering example of silvicultural research in coast Douglas-fir. J For 95(7):19-25

del Rio M, Schütze G, Pretzsch H (2014) Temporal variation of competition and facilitation in mixed species forests in Central Europe. Plant Biol 16(1):166-176

Dieler J, Pretzsch H (2013) Morphological plasticity of European beech (Fagus sylvatica L.) in pure and mixed-species stands. For Ecol Manage 295:97-108

Dippel M (1982) Auswertung eines Nelder-Pflanzverbandsversuches mit Kiefer im Forstamt Walsrode. AFJZ 153:137-154

Duursma RA, Mäkelä A, Reid DEB, Jokela EJ, Porté AJ, Roberts SD (2010) Self-shading affects allometric scaling in trees. Funct Ecol 24:723-730

Enquist BJ, Brown JH, West GB (1998) Allometric scaling of plant energetics and population density. Nature 395:163-165

Enquist BJ, West GB, Brown JH (2009) Extensions and evaluations of a general quantitative theory of forest structure and dynamics. Proc Natl Acad Sci U S A 106:7046-7051

Fahrmeir L, Kneib T, Lang S (2009) Regression. Modelle, Methoden und Anwendungen. Springer, Heidelberg

Forrester DI (2013) The spatial and temporal dynamics of species interactions in mixed-species forests: From pattern to process. For Ecol Manage 312:282-292

Grimm V (1999) Ten years of individual-based modeling in ecology: what have we learned and what could we learn in the future. Ecol Model 115:129-148

Hegyi F (1974) A simulation model for managing Jack-pine stands. In: FRIES J (ed) Growth models for tree and stand simulation. Royal College of Forest, Stockholm, Sweden, pp 74-90

Holmgren M, Scheffer M, Huston MA (1997) The interplay of facilitation and competition in plant communities. Ecology 78(7):1966-1975

Kuehne C, Kublin E, Pyttel P, Bauhus J (2013) Growth and form of Quercus robur and Fraxinus excelsior respond distinctly different to initial growing space: results from 24-year-old Nelder experiments. J For Res 24(1):1-14

Kuoch R (1972) Zur Struktur und Behandlung von subalpinen Fichtenwäldern. Schweiz Z Forstwes 123:77-89

Mäkelä A, Valentine H (2006) Crown ratio influences allometric scaling in trees. Ecology 87:2967-2972

Mayer H, Ott E (1991) Gebirgswaldbau Schutzwaldpflege. Gustav Fischer Verlag, Stuttgart, New York

Munro DD (1974) Forest growth models - a prognosis. In: Fries J (ed) Growth models for tree and stand simulation. Royal College of Forestry, Stockholm Sweden, pp 7-21, Research Notes No. 30

Nelder JA (1962) New kinds of systematic designs for spacing experiments. Biometrics 18(3):283-307

Niklas KJ (2004) Plant allometry: is there a grand unifying theory? Biol Rev $79: 871-889$

Pretzsch H (2005) Stand density and growth of Norway spruce (Picea abies (L.) Karst.) and European beech (Fagus sylvatica L.). Evidence from long-term experimental plots. Eur J For Res 124:193-205

Pretzsch H (2006) Von der Standfächeneffizienz der Bäume zur Dichte-ZuwachsBeziehung des Bestandes. Beitrag zur Integration von Baum- und Bestandesebene, Allgemeine Forst- und Jagdzeitung 177(10):188-199

Pretzsch H (2009) Forest dynamics, growth and yield, from measurement to model. Springer, Berlin, Heidelberg

Pretzsch H (2010) Re-evaluation of allometry: state-of-the-art and perspective regarding individuals and stands of woody plants. In: Lüttge $U$, Beyschlag W, Büdel B, Francis D (eds) Progress in Botany, vol 71, Springer. Berlin, Heidelberg, pp 339-369

Pretzsch H (2014) Canopy space filling and tree crown morphology in mixed-species stands compared with monocultures. Forest Ecol Manage $327: 251-264$ 
Pretzsch H, Dieler J (2012) Evidence of variant intra-and interspecific scaling of tree crown structure and relevance for allometric theory. Oecologia 169(3):637-649

Pretzsch H, Schütze G (2005) Crown allometry and growing space efficiency of Norway spruce (Picea abies (L.) Karst.) and European beech (Fagus sylvatica L.) in pure and mixed stands. Plant Biol 7(6):628-639

Price CA, Gilooly JF, Allen AP, Weitz JS, Niklas KJ (2010) The metabolic theory of ecology: prospects and challenges for plant biology. New Phytol 188:696-710

Purves DW, Lichstein JW, Pacala SW (2007) Crown plasticity and competition for canopy space: A new spatially implicit model parameterized for 250 North American tree species. PLoS One 2:e870

Reineke LH (1933) Perfecting a stand-density index for even-aged forests. J Agric Res 46:627-638

Spellmann H, Nagel J (1992) Auswertung des Nelder-Pflanzverbandsversuches mit Kiefer im Forstamt Walsrode. Jahresbericht Sektion Ertragskunde 1992 in Grillenburg/Sachsen, Deutscher Verband Forstlicher Forschungsanstalten., pp 149-161

Sterba H (1999) 20 years target diameter thinning in the "Hirschlacke", forests of the monastery of Schlägl. Allgemeine Forst- und Jagdzeitung 170(9):170-175

Sterba H, Amateis RL (1998) Crown efficiency in a loblolly pine (Pinus taeda) spacing experiment. Can J For Res 28(9):1344-1351

Tennent RB (1975) Competition quotient in young Pinus radiate. NZ J For Sci 5(2):230-234

Turner R (2014) deldir: Delaunay Triangulation and Dirichlet (Voronoi) Tessellation. R package version 0.1-6. http://CRAN.R-project.org/package=deldir. Accessed 15 Oct 2014

Vanclay JK, Lamb D, Erskine PD, Cameron DM (2013) Spatially explicit competition in a mixed planting of Araucaria cunninghamii and Flindersia brayleyana. Ann For Sci 70:611-619

von Lüpke B, Spellmann H (1997) Aspekte der Stabilität und des Wachstums von Mischbeständen aus Fichte und Buche als Grundlage für waldbauliche Entscheidungen. Forstarchiv 68:167-179

von Lüpke B, Spellmann H (1999) Aspects of stability, growth and natural regeneration in mixed Norway spruce-beech stands as a basis of silvicultural decisions. In: Olsthoorn AFM, Bartelink HH, Gardiner JJ, Pretzsch H, Hekhuis $\mathrm{HJ}$, Franc A (eds) Management of mixed-species forest: silviculture and economics, vol 15, IBN Scientific Contributions., pp 245-267

Webster CR, Lorimer CG (2003) Comparative growing space efficiency of four tree species in mixed confer-hardwood forests. Forest Ecol Manage 177:361-377

West GB, Brown JH, Enquist BJ (1997) A general model for the origin of allometric scaling laws in biology. Science 276:122-126

West GB, Enquist BJ, Brown JH (2009) A general quantitative theory of forest structure and dynamics. Proc Natl Acad Sci U S A 106:7040-7045

Wood SN (2011) Fast stable restricted maximum likelihood and marginal likelihood estimation of semiparametric generalized linear models. J R Stat Soc (B) 73(1):3-36

Zeide B (1987) Analysis of the 3/2 power law of self-thinning. For Sci 33:517-537

Zeide B (2001) Thinning and growth: A full turnaround. J For 99:20-25

Zeide B (2002) Density and the growth of even-aged stands. For Sci 48:743-754

Zuur A, Leno EN, Walker N, Saveliev AA, Smith GM (2009) Mixed effects models and extensions in ecology with R. Springer, Heidelberg

\section{Submit your manuscript to a SpringerOpen ${ }^{\circ}$ journal and benefit from:}

- Convenient online submission

- Rigorous peer review

- Immediate publication on acceptance

- Open access: articles freely available online

- High visibility within the field

- Retaining the copyright to your article

Submit your next manuscript at $>$ springeropen.com 